Piotr Furtak, Michał Ceremuga and Jerzy Siczek

\title{
1. RADIATION AND DEFENSE AGAINST NUCLEAR WEAPONS
}

Radiation is the sending and transfer of energy at a distance. Energy can be sent in the form of heat, light (as electromagnetic waves or molecules). In the general sense, we are called a radiation electromagnetic waves (EM) propagated in an appropriate medium (vacuum, the earth's atmosphere, water, other example. Soil). In addition to electromagnetic waves, there are other waves, eg acoustic or gravitational waves which in colloquial speech we do not call radiation.

In our environment there are many different sources of radiation in the form of electromagnetic waves - both as sources of natural and artificial.

A typical example of such waves are radio waves and light. Radio waves are of natural origin (star) and artificial (radio and television signals produced by the human radar, mobile telephony, etc.). Also, light can be of natural origin (starlight, some living organisms, fire) and artificial (light sources created by man - lamps, radiators). A particular type of radiation is ionizing radiation. They were called because it induced in electrically neutral atoms and molecules of charge change, i.e. ionization.

Man is not equipped by nature with any sense that allows him to feel the presence of ionizing radiation as, for example, our eyes detect and react to light. Therefore, to be able to detect the presence of radiation was necessary to build devices that can we "help" visualize his presence.

Ionizing radiation comes from space, rocks, air and human activity. Ionizing radiation, both natural and artificial, is a part of our environment and is present everywhere. This part of the ionizing radiation that man has created is used in industry, medicine and energy. Therefore, you should be aware of its presence and know the basic principles that apply to its use, taking into account the potential dangers it may bring.

\subsection{Properties of radiation}

Each electromagnetic wave has three parameters associated with each other, which characterize it unequivocally. These are:

- Length - marks as a Greek letter lambda $[\lambda]$;

- Frequency - marks as a Greek letter ni [v];

- Energy - marks as a Latin letter E. 
Between these values there is a relationship:

- $\mathbf{E}^{*}=\mathbf{h} \boldsymbol{v}$ - where " $h$ " is Planck's constant, or

- $\mathbf{E}=\mathbf{h} \mathbf{c} / \boldsymbol{\lambda}$ - where "c" is the speed of light in a vacuum.

The illustration below shows a graphical relationship between these values.

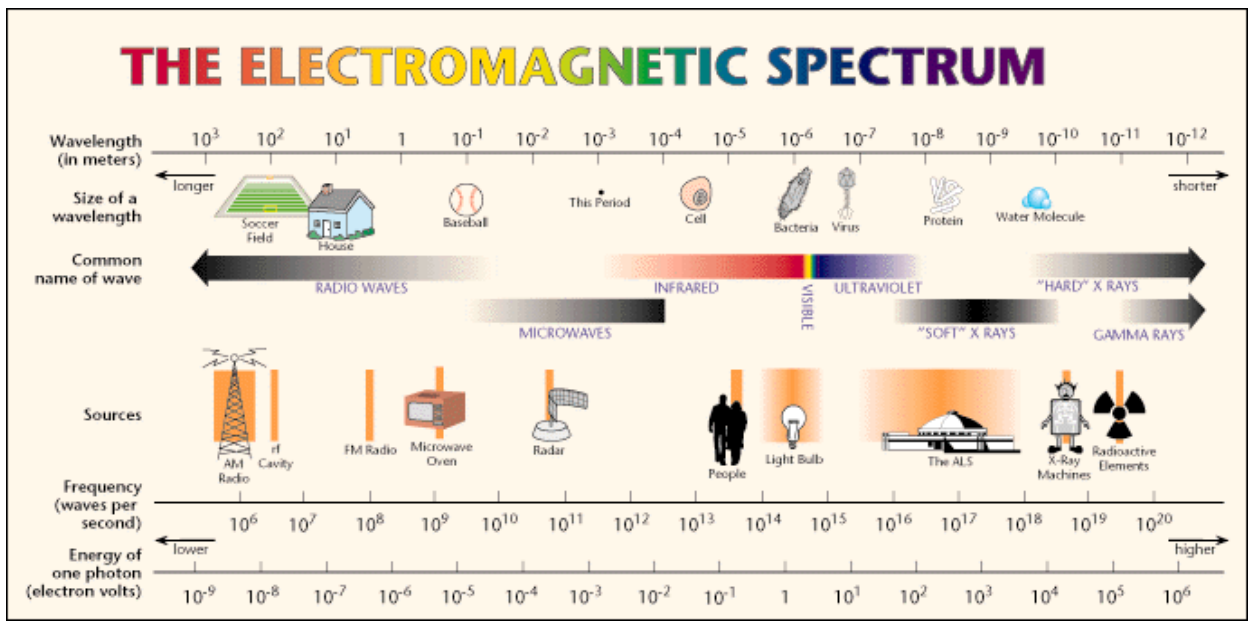

Figure 1. The spectrum of electromagnetic waves (figure used with permission under Creative Commons license)

As can be seen from the graph above, there is a fairly strict division into non-ionizing and ionizing radiation. In terms of lower energy, it begins from the ultraviolet with increasing energy is becoming more and more dangerous.

Used to scale the energy unit "electron volt" (termed "eV") energy is one which is replaced by an electron accelerated in the electric field the potential difference of $1 \mathrm{~V}$

$1 \mathrm{eV}=1,6 \times 10^{-19} \mathrm{~J}$, which is a unit of very small. In practice, we use a larger unit, ie. $\mathrm{keV}$ and $\mathrm{MeV}$. From the point of view of the SI measurement system, the electronvolt is a system-non-system unit, but allowed for use in nuclear technology.

\subsection{Types of radiation ( $\alpha, \beta, X$-rays, neutrons)}

To talk about radiation and radioactivity, the theory of the atomic structure should be brought closer to the listeners. Of course, in the form of a lightweight so that you can later was part of the lecture to refer to the definitions and phenomena listed here.

We will use here the so-called classical model of the atom. Rutherford's model. Ernst Rutherford with Henri Becquerel and Marie Curie form part of the groups of researchers pioneers in the field of research into the structure and 
atom and radioactivity phenomenon at the turn of the century. Our compatriot Maria Skłodowska-Curie was the first victim of radioactivity, because she died as a result of radiation sickness.

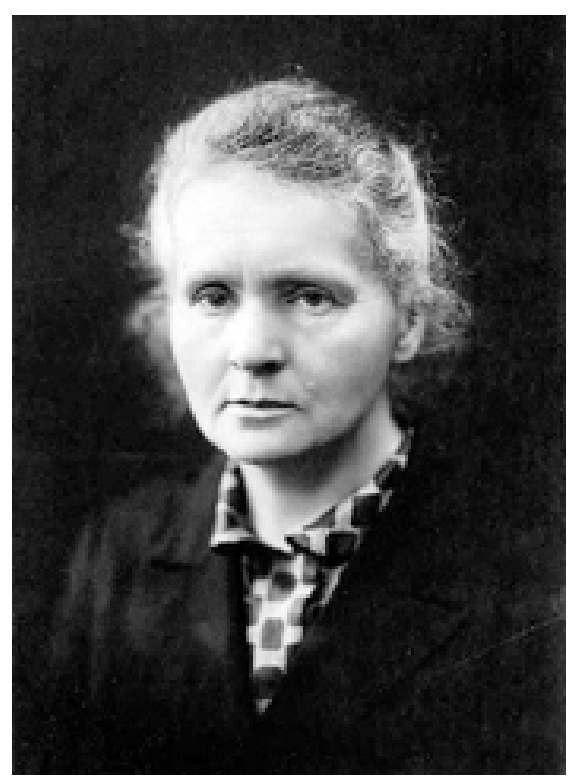

Figure 2. Maria Skłodowska-Curie (figure used with permission under Creative Commons license)

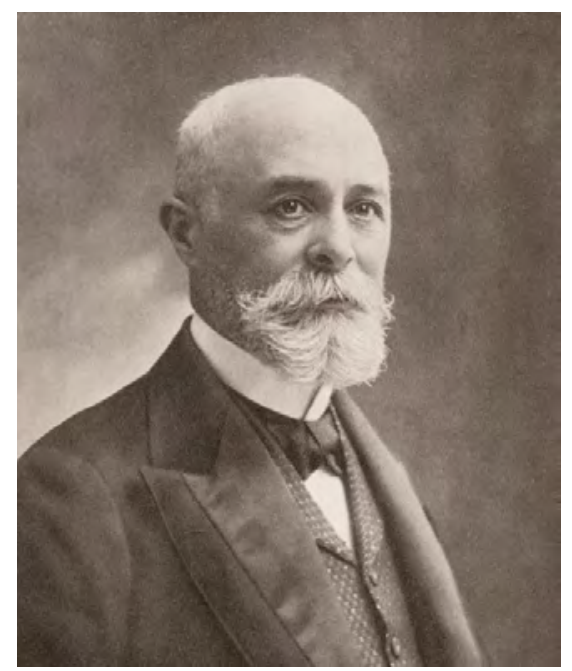

Figure 3. Henri Becquerel (figure used with permission under Creative Commons license) 


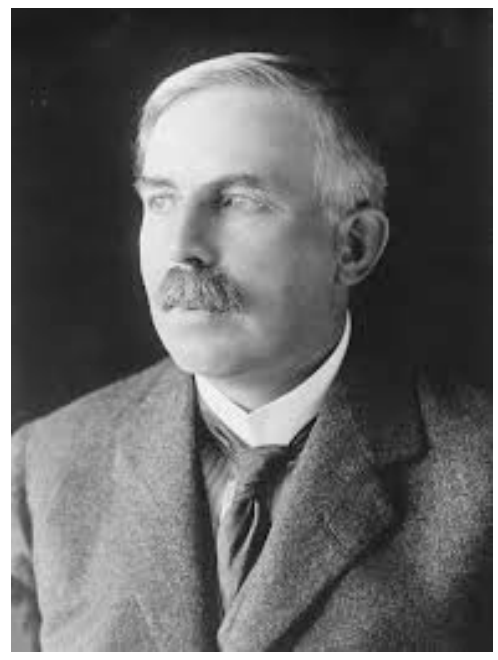

Figure 4. Ernst Rutherford (figure used with permission under Creative Commons license)

The model of the Rutherford atom assumed the existence of an atomic nucleus revolve around which electrons elliptical orbits. This model is now a good basis for the lecture on 'atomistics in a nutshell'.

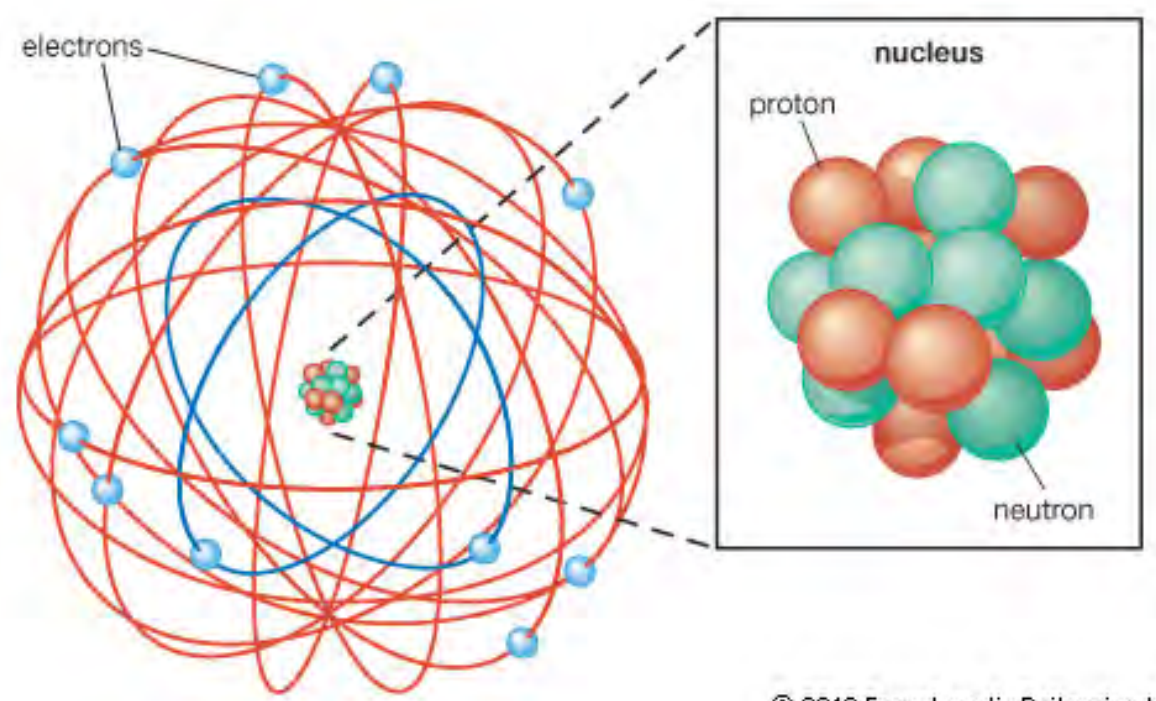

(G) 2012 Encyclopedia Britannica, Inc.

Figure 5. Rutherford atom model. On the left a positive nucleus surrounded by clouds of negative electrons circulating on elliptical orbits. On the right larger core composed of positive protons and electrically neutral neutron (figure used with permission under Creative Commons license) 
Weight of proton and a neutron in they are approximately equal to each other while the mass of the electron is smaller than the mass of the proton and ne at the throne 1840 times. If you compare the diameter of the nucleus and the diameter of the atom, it turns out that the atom in the middle is "empty".

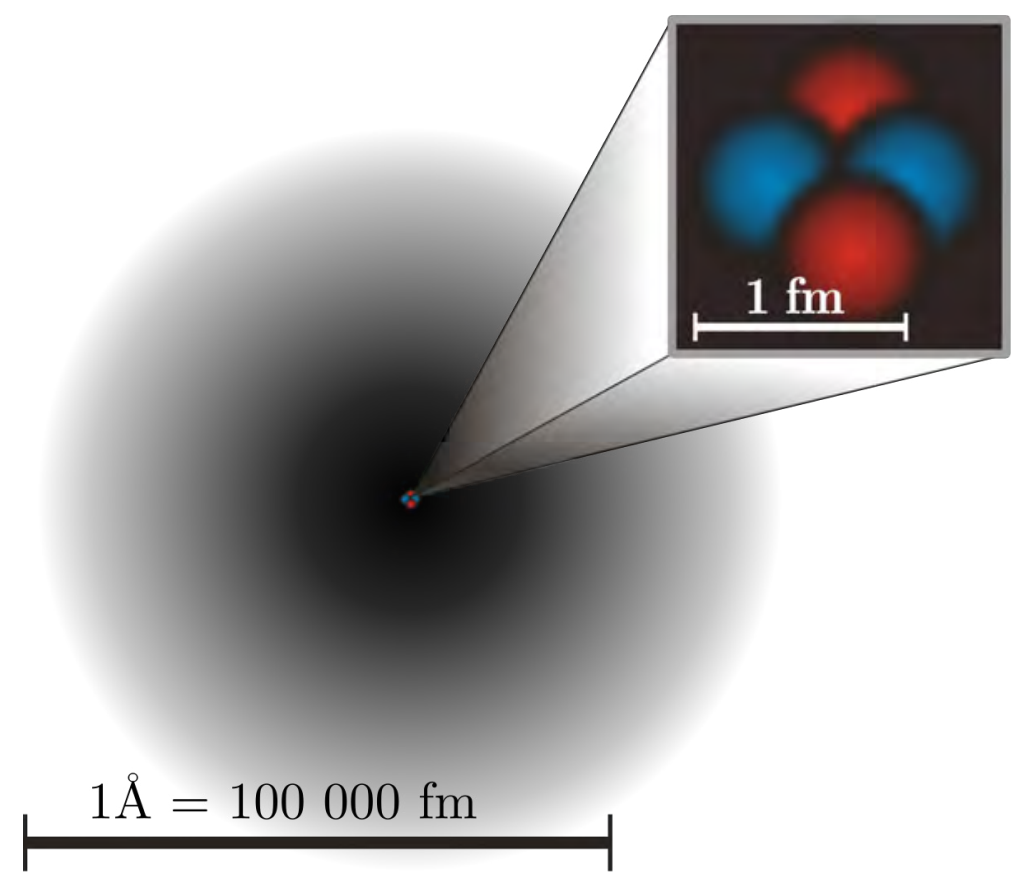

Figure 6. Schematic comparison of the size of the helium atomic nucleus $(1 \mathrm{fm})$ and the diameter of the helium atom $(1 \AA=100,000 \mathrm{fm})$ (figure used with permission under Creative Commons license)

The electric charge of the proton and electron is the same in magnitude, with the proton having a positive charge and the negative electron. From the standpoint of physics atom of any element by its nature it is electrically neutral.

A cloud of electrons orbiting the nucleus is called the electron shell. If this coating by an external factor is added to or included as one or more electrons to an atom receive ion with the proviso that if electrons are added to the shell to receive a negative ion, and if included is receive positive ion.

Each atom is distinguished by the number of protons in the nucleus. Hydrogen has a nucleus of one proton, helium 2 protons, lithium 3 protons and uranium 92 protons.

There are elements of so-called uranium other than uranium. transuranic (prepared artificially, the current has reached the atomic number 118). In addition to protons in the nucleus they are also neutral molecules called neutrons. 
Common name of neutrons and protons in the nucleus of a nucleons. The nature of element tells us the number of protons in the nucleus marked with the letter " $Z$ " - this is the atomic number in the periodic table (the Periodic Table of the Elements - PTOE). A second parameter characterizing atom is its atomic mass representing the number of nucleons in the nucleus marked with letter $\mathrm{A}$. The overall record of the atom of the element:

Atomic / mass number - this is the sum of the protons and neutrons

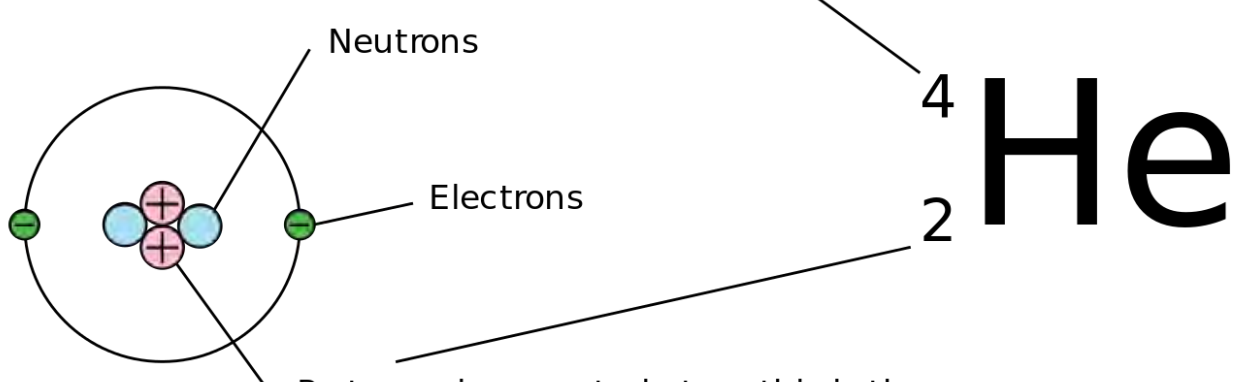

Protons - in a neutral atom this is the same as the number of electrons

Figure 7. Explanation of mass number and atomic number (figure used with permission under Creative Commons license)

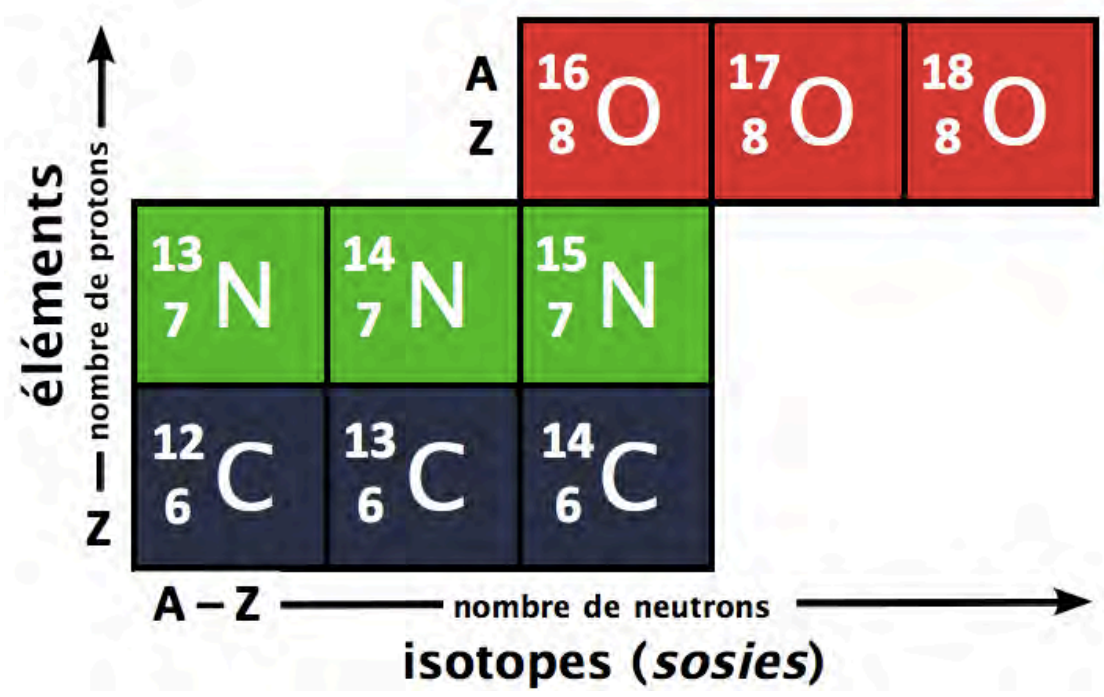

Figure 8. Isotopes of oxygen, nitrogen and carbon (figure used with permission under Creative Commons license) 
As indicated, the atoms of a given element must have the same number of protons, but it often happens that they differ in the number of neutrons. Because the PTOE such atoms will be classified in the same place it was called isotopes (from the Greek "isos topos" - the same place.) Another name for this isotope nuclide. There is also a concept isobar ie. Two atoms of different elements having the same mass number.

The simplest example is the hydrogen isotopes:

- Prot -1 proton in the nucleus;

- Deuterium - 1 proton and 1 neutron in the nucleus;

- Tritium - 1 proton and 2 neutrons in the nucleus.

Prot and deuterium are stable isotopes and tritium is a radioactive isotope.

\section{PERIODIC TABLE OF THE ELEMENTS}

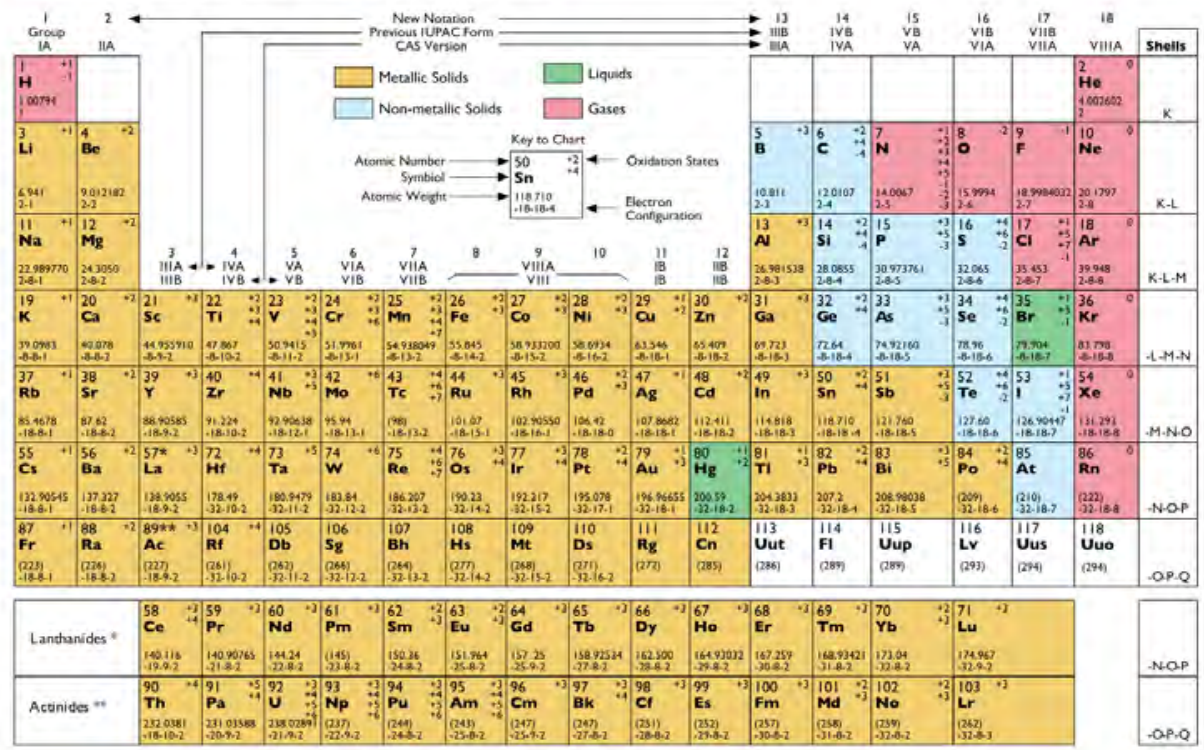

Figure 9. Periodic table of elements (figure used with permission under Creative Commons license)

From the physical point of view, ionization can be caused by particles or electromagnetic waves. The molecular radiation are also talking about the radiation of corpuscular. The particles that cause ionization can be divided into ionizing directly or indirectly.

In area electromagnetic waves dealing with $\mathbf{X}$-rays and gamma rays as ionizing radiation. In the area of particle radiation, we deal with alpha, beta, neutron and other radiation, e.g. proton or deuteron streams. 
ISOTOPES

Atoms having same atomic number but different mass numbers.

${ }^{123} \mathrm{I},{ }^{125} \mathrm{I},{ }^{127} \mathrm{I},{ }^{131} \mathrm{I}$
ISOBARS

Atoms having same number of nucleons but differ in number of protons i.e. have same mass number and different atomic number.

$$
{ }^{40} \mathrm{Cl},{ }^{40} \mathrm{Ar},{ }^{40} \mathrm{~K},{ }^{40} \mathrm{Ca}
$$

Figure 10. Isotopes vs Isobars

Of alpha, beta, protons or deuterons and other heavier particles are ionizing particles directly. This means that the neutral electrically atoms and molecules are ionized as a result of electrostatic interactions. From the point of view of physics:

- Alpha particles are helium nuclei;

- Beta particles are simply a stream of electrons;

- Protons are hydrogen nuclei;

- Deuterons are deuterium nuclei (1 proton and 1 neutron).

Indirectly ionizing particles are neutrons. Electromagnetic radiation or $\mathrm{X}$-rays and gamma rays include ionizing radiation indirectly. Electromagnetic ionizing radiation is divided into:

- X-ray radiation. such that arises due to the interaction of charged particles (electrons) of the electron shell of the atom;

- Gamma radiation, i.e. radiation, which source is the nucleus of the atom.

In turn, the $\mathbf{X}$-rays are divided into:

Characteristic Radiation - the impact of the electron beam knock off electrons from the electron shell of atom. Electrons returning to his seat quantum emit radiation, whose energy is closely related to the atomic number " $Z$ " material, which allows you to identify it. This identification method is used in X-ray fluorescence analysis or X-ray spectrometry in electron microscopes.

Bremsstrahlung - it is formed when the electron beam interacts with an electric field an electron shell as a whole. Inhibition of the phenomenon of radiation is used to generate radiation beams " $\mathrm{X}$ " for applications in the industrial field (X-ray radiography), Medical X-ray cameras and security. This radiation is also produced as an undesirable by-product, when used the electron beam for welding of metals. 


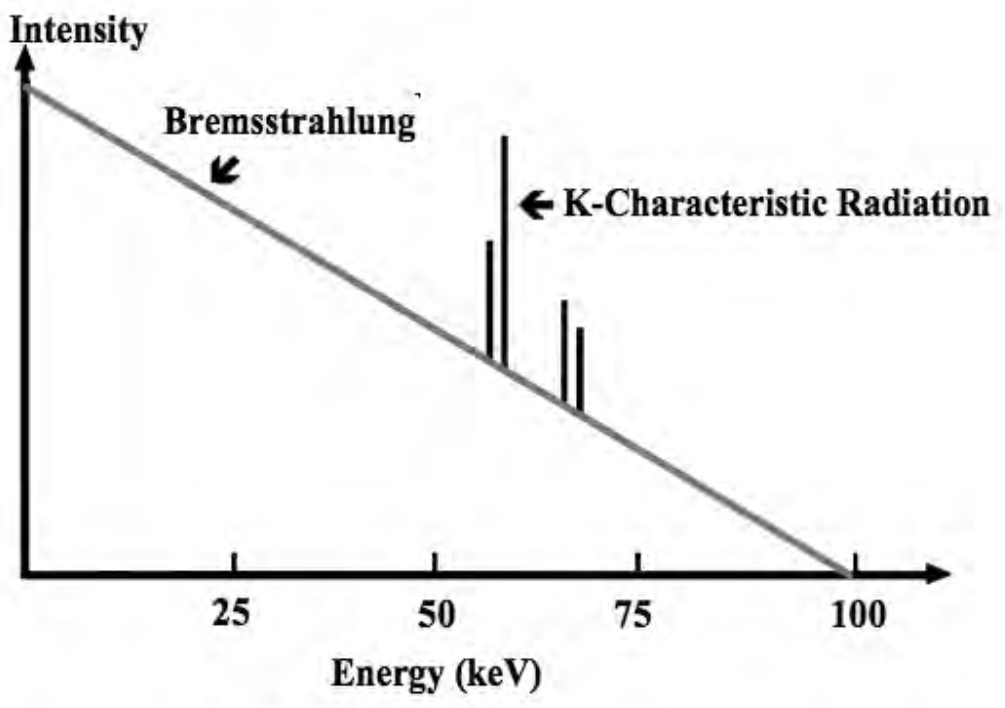

The X-ray spectrum from tungsten

Figure 11. X-rays spectrum with Bremsstrahlung part and characteristic part (figure used with permission under Creative Commons license)

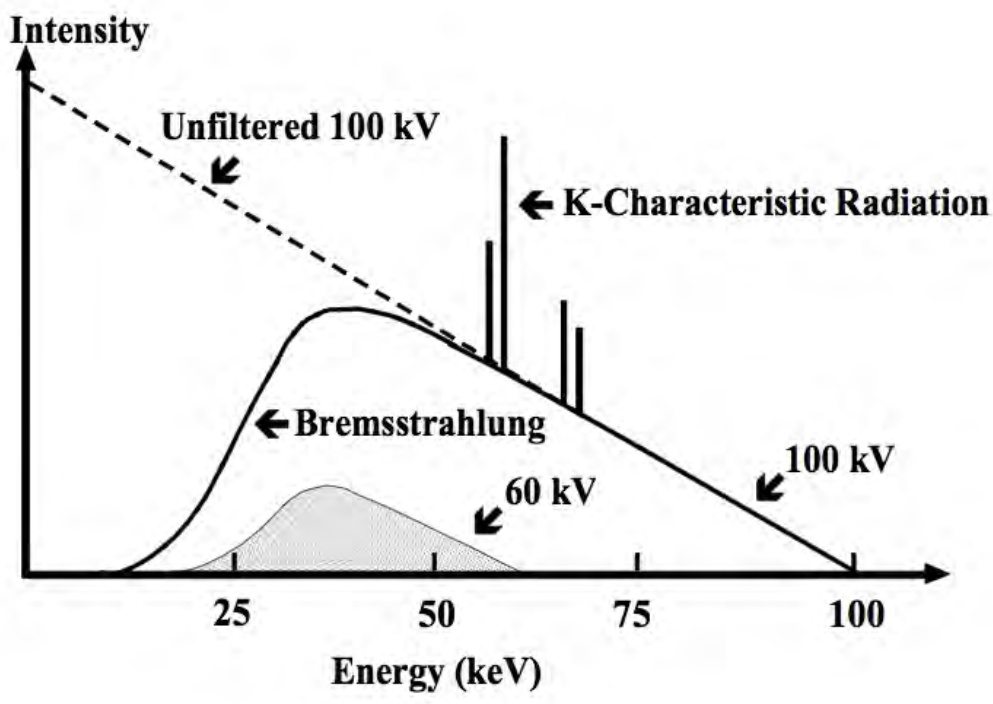

Figure 12. X-ray spectrum for low and high accelerating voltage (figure used with permission under Creative Commons license) 


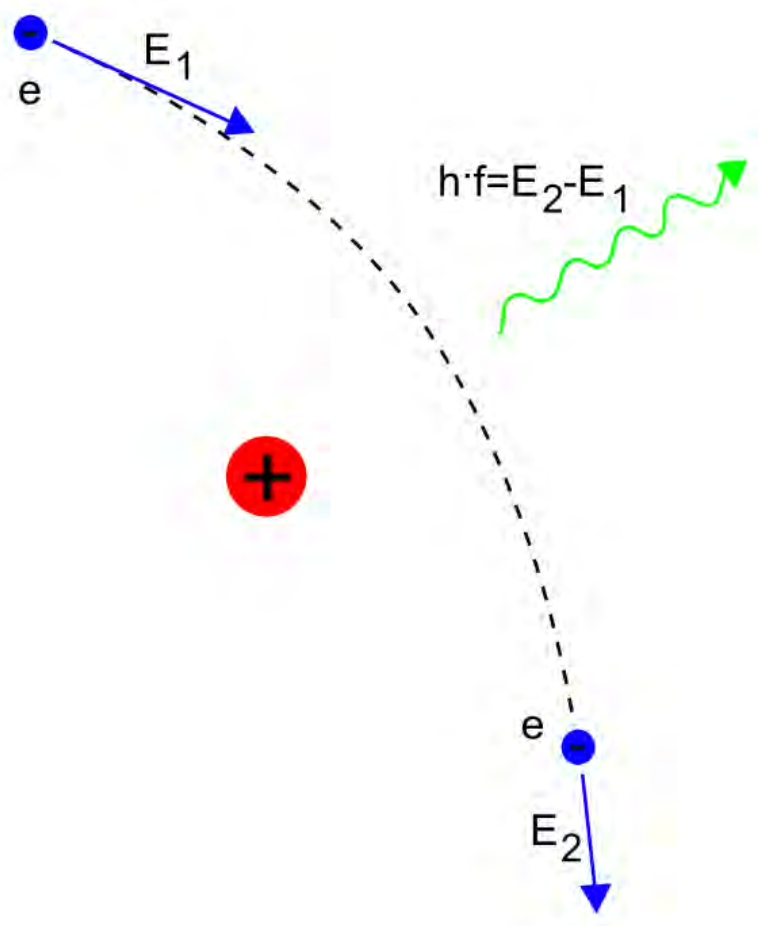

Figure 13. Explanation how Bremsstrahlung radiation is produced

\section{Gamma radiation}

Gamma radiation arises as a result of nuclear transformations that take place in the nuclei of radioactive isotopes. The emission of gamma radiation in most cases is composite, i.e. with the accompanying emission of alpha or beta radiation or both at the same time.

\section{Energy ranges}

As mentioned before, every EM wave including the waves of ionizing radiation has a parameter that characterizes it, i.e. energy.

Also, they charged particles or uncharged (alpha, beta, protons, neutrons) have an energy, which together with the properties of said particles is characterized by any type of radiation.

Alpha decay - emission of the He 4 nucleus stream. Discrete spectrum. Tick s energy of particles emitted from a few to several $\mathrm{MeV}$. 
Beta decay - electron beam emission. Continuous spectrum. Energy range $\mathrm{E}_{\text {max }}$ to a few $\mathrm{MeV}$.

The transformation of gamma - quantum emission stream. Discrete spectrum. The scope of energy to a few $\mathrm{MeV}$.

\subsection{Radiation properties}

\subsubsection{Radioactive decay: scheme and parameters}

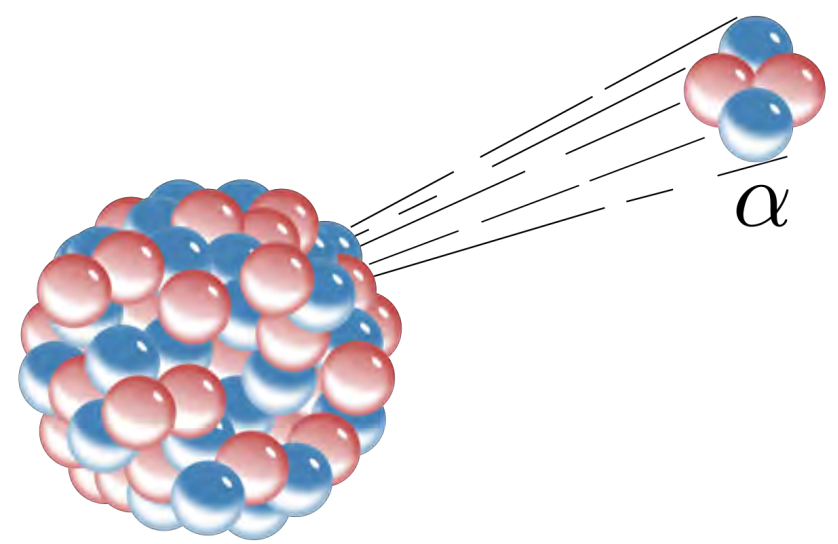

Figure 14. Graphical representation of the alpha decay. The kernel drops an alpha molecule (figure used with permission under Creative Commons license)

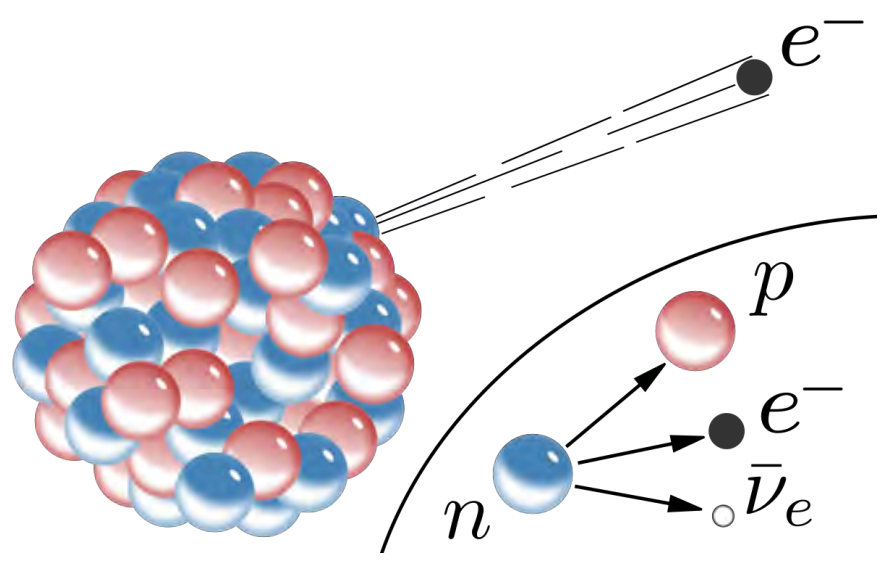

Figure 15. Chart of beta decay. The neutron in the nucleus decays into a proton and an electron (figure used with permission under Creative Commons license) 


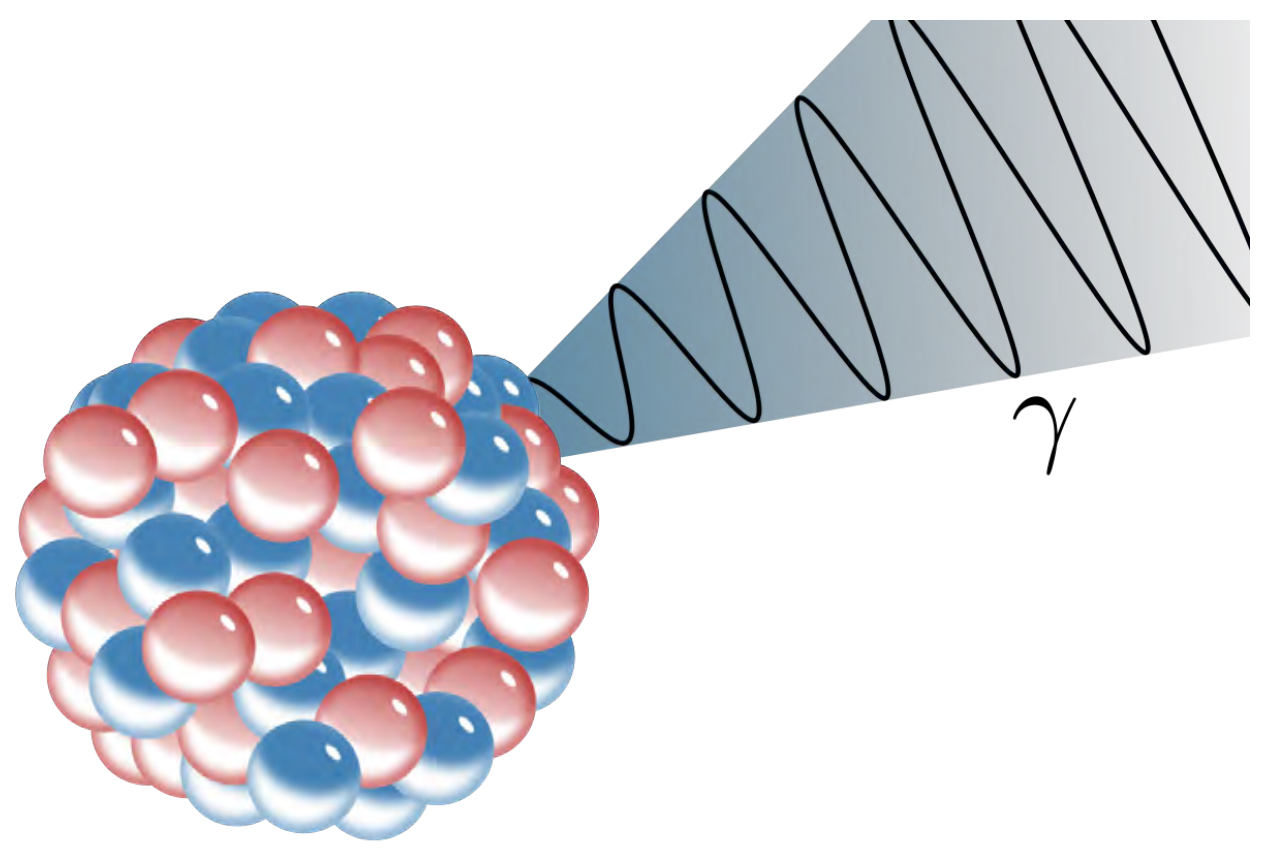

Figure 16. Chart of the conversion gamma (figure used with permission under Creative Commons license)

The pictures above illustrate graphically the alpha and beta decay and gamma transformation. Phenomena most often occur together, i.e. the alpha or beta decay is accompanied by the emission of gamma quanta. There are nuclides that are pure alpha or beta emitters.

In ancient world atom (from Greek "a-tomos" - no split able) was found as smallest part of environment. Now in XXI century we know that not only atom can divided in parts (nuclear reaction like fission or spallation) but even kernel is a complex structure in real not only consist of protons and neutrons.

Of course it is some simplification to say - we have only protons and neutrons. It is very useful to explain some nuclear phenomena but reality is more complicated.

Only for example you will find on image below how current science describe whole atom and its nucleus on Helium element. 


\section{A helium atom}

Gluons - subatomic particles that cause quarks to interact and protons to interact with neutrons in the atom nuclel.

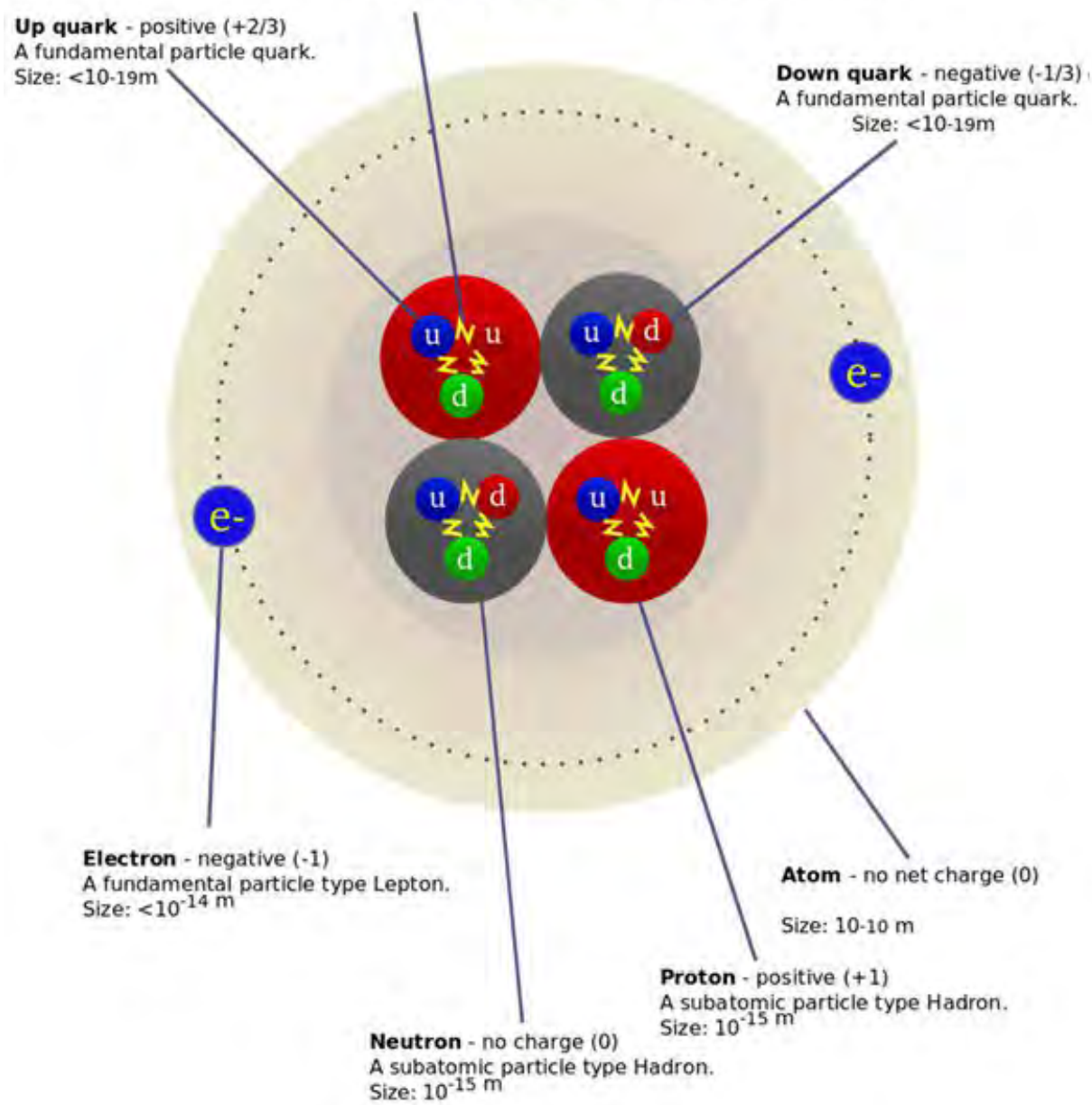

Figure 17. Detailed description of helium atom including nucleus structure (figure used with permission under Creative Commons license) 


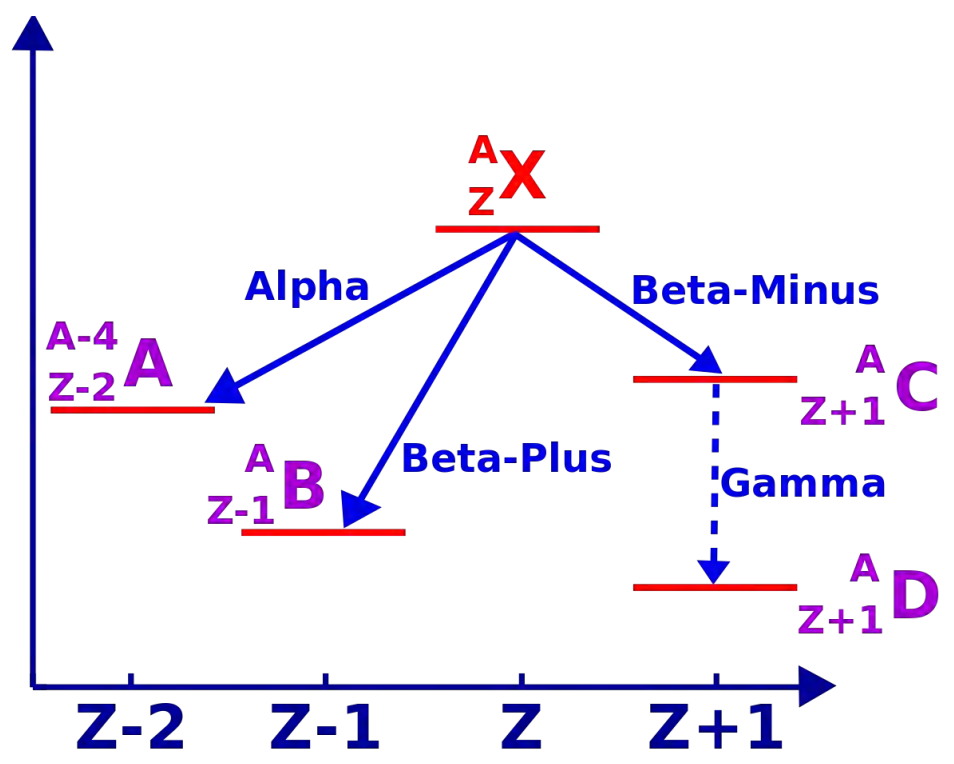

Figure 18. Nuclear decay parameters, Vertical axis - Energy, Horizontal axis - Atomic number

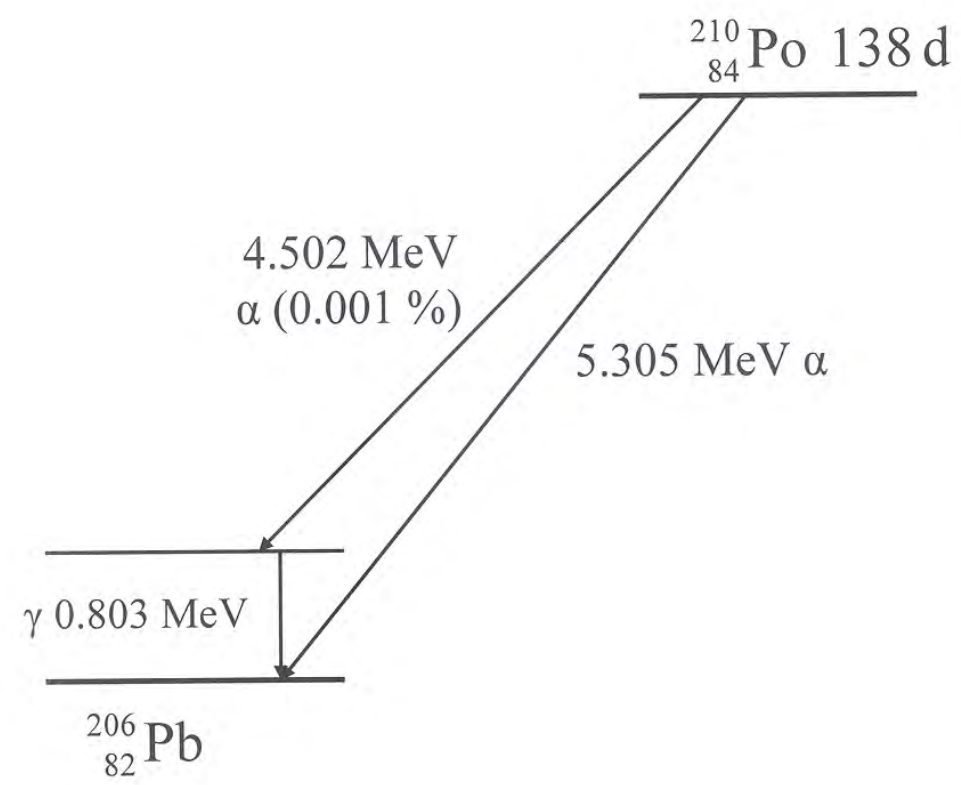

Figure 19. Scheme decay of polonium-210. Visible alpha decays and the accompanying transition and gamma (figure used with permission under Creative Commons license) 


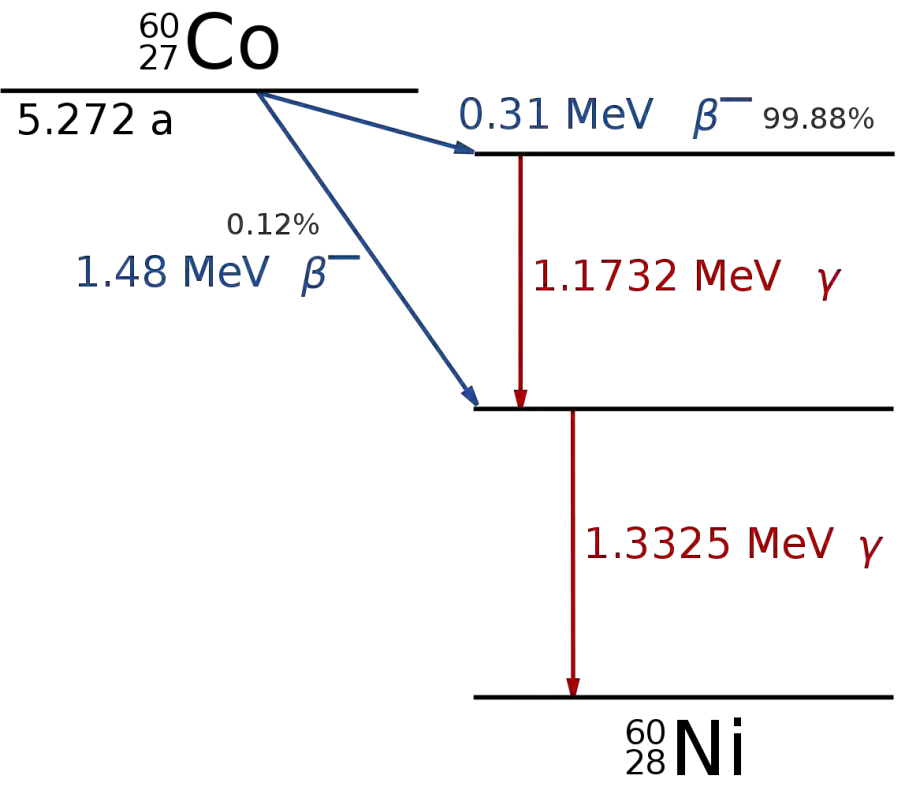

Figure 20. Schematic diagram of Co-60 cobalt disintegration. See two 1.33 and $1.17 \mathrm{MeV}$ gamma transitions (figure used with permission under Creative Commons license)

\subsection{Radiometry - basic parameters}

The discovery of the phenomenon of radioactivity occurred in principle quite accidentally. Becquerel during the study of uranium ore kept it wrapped in black paper and photographic film. After developing the film, it turned out that it was exposed. The scholars began to wonder what could have caused the film to be exposed, and so began in the history of the human era of the atom.

At the beginning, they were not aware that research on radioactivity is associated with some danger. However, in an effort to define a certain size were introduced certain concepts. They gave rise to science called radiometry and its derivative dosimetry.

Concepts used in radiometry:

- Law of atomic decay. When studying nuclear decays and transformations, a certain regularity was observed when measuring radiation. This resulted in the formulation of the law of atomic decay:

- This law determines how the processes of radioactive decay take place. For each nuclide, there is a unique set the speed at which it disintegrates. 
- The rate of decay is exponential nature of the evanescent i.e. that the rate of decay of the radiation is a function of the general type $\exp (-x)$ where " $x$ " is the unit of time.

- And defined the concept of activity is given in units which will be measured. These units evolved over time to be consistent with the international system of SI measures.

- To be able to speak about the effects of physical activity introduces the concept of radiation dose radiation.

- To be able to talk about the biological effects of the concept of equivalent doses in relation to man and his organs.

\subsection{Types of radiation doses and units used in radiological protection}

In radiation science, the concept of radiation doses was introduced and thus defined:

- Absorbed dose - D = dE/dm - Unit J/kg (Gy);

- Equivalent dose $-\mathrm{H}_{\mathrm{T}}=\mathrm{D}^{*} \mathrm{~W}_{\mathrm{R}}-\mathrm{Unit} \mathrm{J} / \mathrm{kg}(\mathrm{Sv})$;

- Effective dose $-\mathrm{E}=\mathrm{H}_{\mathrm{T}}{ }^{*} \mathrm{~W}_{\mathrm{T}}$ - Unit $\mathrm{J} / \mathrm{kg}(\mathrm{Sv})$.

The absorbed dose is the amount of energy dissipated in the ionization mass. There is a physical unit and describes the energy effects. Equivalent dose is the absorbed dose, taking into account the coefficient $\mathbf{W}_{\mathrm{R}}$ that takes into account the biological effects associated with different types of radiation being absorbed. Effective Dose (RMS) introduces a factor $\mathbf{W}_{\mathrm{T}}$ ie the weight factor of tissues taking into account the sensitivity of individual organs and tissues to radiation.

Due to distinguish between different types of dose, although each of them has a physical dimension $[\mathrm{J} / \mathrm{kg}]$ is a unit of absorbed dose in gray $(\mathbf{G y})$ and the other two are located in the unit sivert $(\mathbf{S v})$. Sivert is a unit of all doses related to the exposure of a living organism. In the case of exposure to various types of radiation and exposure of various organs, we use the sum of exposure from different types of radiation and various organs.

$$
\begin{aligned}
& H=\sum_{i} D_{i} * W_{R i} \\
& E=\sum_{i} H_{i} * W_{T i}
\end{aligned}
$$

Below the image presents the compares doses absorbed in some real circumstances with dose limits on US NRC regulatory. 


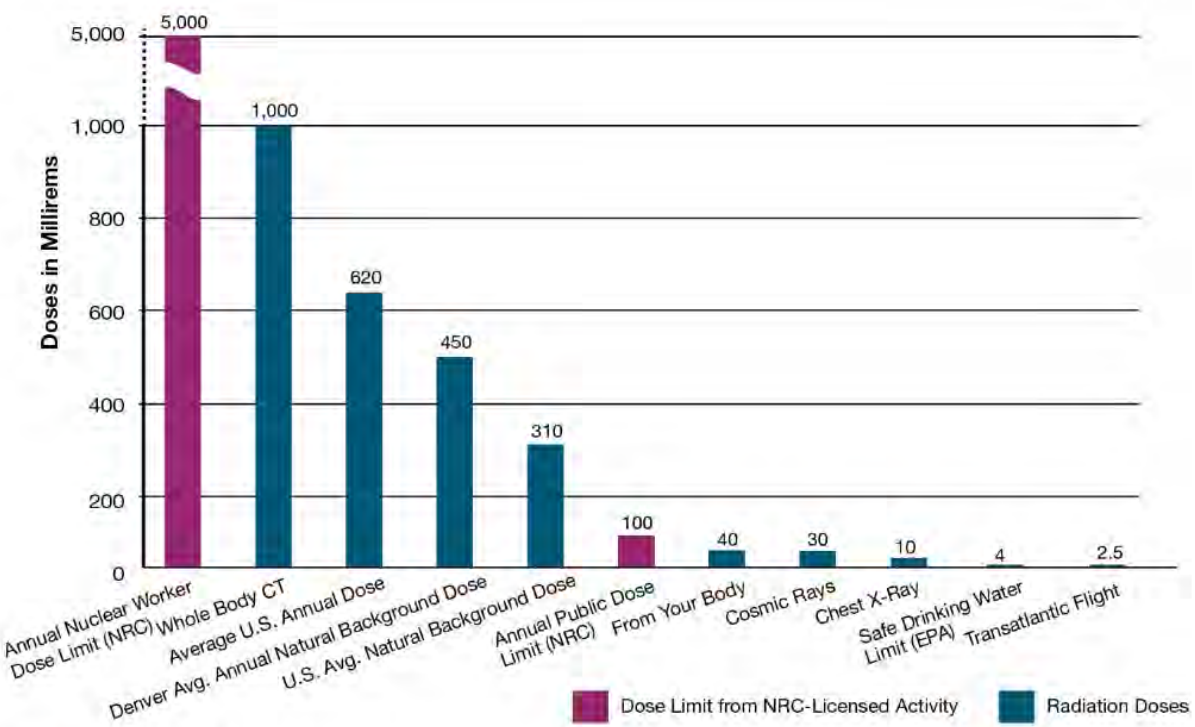

\section{? U.S.NRC}

Figure 21. Radiation doses and Regulatory Limits by US NRC. In USA still old units are in use. Conversion from mrem to $\mathrm{mSv}$ is $1 \mathrm{mrem} \Leftrightarrow 0.01 \mathrm{mSv}$ (figure used with permission under Creative Commons license)

\subsection{Radioactive isotopes: the concept of half-life and activity}

The law of radioactive decay gives the way in which the number of atoms of a given nuclide decreases.

$$
N(t)=N_{0} e^{-\lambda t}
$$

Where:

$\mathrm{N}_{0}$ - the number radioactive atoms at the beginning of life of source, $\mathrm{N}(\mathrm{t})$ - number of radioactive atoms at time " $\mathrm{t}$ ", $\lambda$ - constant of radioactive decay.

The radioactive decay constant determines the rate at which radioactive atoms "disappear". At the moment, we are introducing the concept of the half-past period.

$\mathrm{T}_{1 / 2}=>$ Is the period which is half of the radioactive atoms.

There is relation between half time period and constant of radioactive decay

$$
\lambda^{*} \mathrm{~T}_{1 / 2}=\ln 2
$$


The half-life period is also referred to as the half-life time.

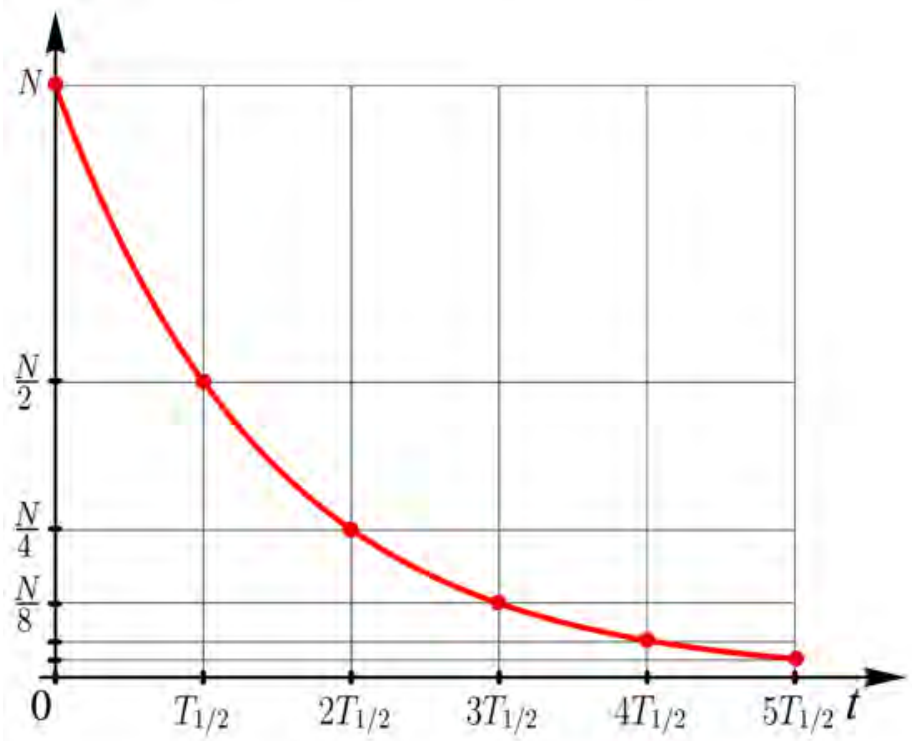

Figure 22. Graphic illustration of the law of radioactive decay. After each half-life, the number of radioactive atoms decreases twice (figure used with permission under Creative Commons license)

Radioactive activity is simply the number of radioactive atoms that break down in a unit of time.

$$
\mathrm{A}=-\mathrm{dN} / \mathrm{dt}
$$

After transformation we obtain a pattern corresponding to the pattern of the number of atoms disintegrating:

$$
A(t)=A_{0} e^{-\lambda t}
$$

$A_{0}$ - is the source activity at the time of production,

$A(t)$ - Is the source activity after time $t$,

Value $A_{0}$ is a parameter which is given for radioactive sources while source is manufactured. Value of $A_{0}$ is written in source certificate.

We measure our activity in Becquerels (a unit named after $\mathrm{H}$. Becquerel). $1 \mathrm{~Bq}$ is 1 disintegration per second $\left(\mathrm{s}^{-1}\right)$, so it is very small unit. Practically we use a larger unit $\mathrm{kBq}, \mathrm{MBq} \mathrm{GBq}$ and $\mathrm{TBq}$.

The historical unit is a kiur named after Maria Skłodowska-Curie. It has a practical basis because the activity of $1 \mathrm{Ci}$ had $1 \mathrm{~g}$ Ra-226 produced by Maria 
and donated to Poland. In turn, $\mathrm{Ci}$ unit was very high and practically used his aliquots ie. $\mathrm{mCi}, \mathrm{uCi}, \mathrm{nCi}$. The relationship between these units is $\mathbf{1 ~} \mathbf{C i}=\mathbf{3 7} \mathbf{~ G B q}$.

Sometimes, some literature position and companies still $\mathrm{Ci}$ is using to determine the activity of sources. For example Smiths Detection in GID-3 manual has Ni-63 sources in $\mathrm{mCi}$ described.

\subsection{Sources of radiation}

\subsubsection{Natural radioactivity}

As mentioned earlier, radioactivity occurs naturally in nature. Radioactive elements that occur in air, soil and water together with cosmic radiation make up the radioactive background that surrounds us.

\section{Radioactive elements found in nature}

The elements that occur naturally in nature are:

- Coal C-14;

- Potassium K-40;

- Three elements of the so-called. radioactive ranks;

- Others listed in the figure below.

\begin{tabular}{|c|c|}
\hline Element & Half-life (years) \\
\hline${ }^{235} \mathrm{U}$ & $7 \times 10^{8}$ \\
\hline${ }^{238} \mathrm{U}$ & $4.47 \times 10^{9}$ \\
\hline${ }^{232} \mathrm{Th}$ & $1.4 \times 10^{10}$ \\
\hline${ }^{176} \mathrm{Lu}$ & $3.6 \times 10^{10}$ \\
\hline${ }^{187} \mathrm{Re}$ & $4.3 \times 10^{10}$ \\
\hline${ }^{87} \mathrm{Rb}$ & $4.9 \times 10^{10}$ \\
\hline${ }^{138} \mathrm{La}$ & $1 \times 10^{11}$ \\
\hline${ }^{147} \mathrm{Sm}$ & $1.05 \times 10^{11}$ \\
\hline${ }^{190} \mathrm{Pt}$ & $6.9 \times 10^{11}$ \\
\hline
\end{tabular}

Figure 23. Naturally radioactive isotopes. The first three marked in red are the origins of three natural radioactive ranks

\subsection{Radioactive seriess}

There are 4 radioactive series. Below are shown graphical representation of them. Due to fact that emitting alpha particle mass number of daughter element decreases by 4 from its parent it can be only four series. 


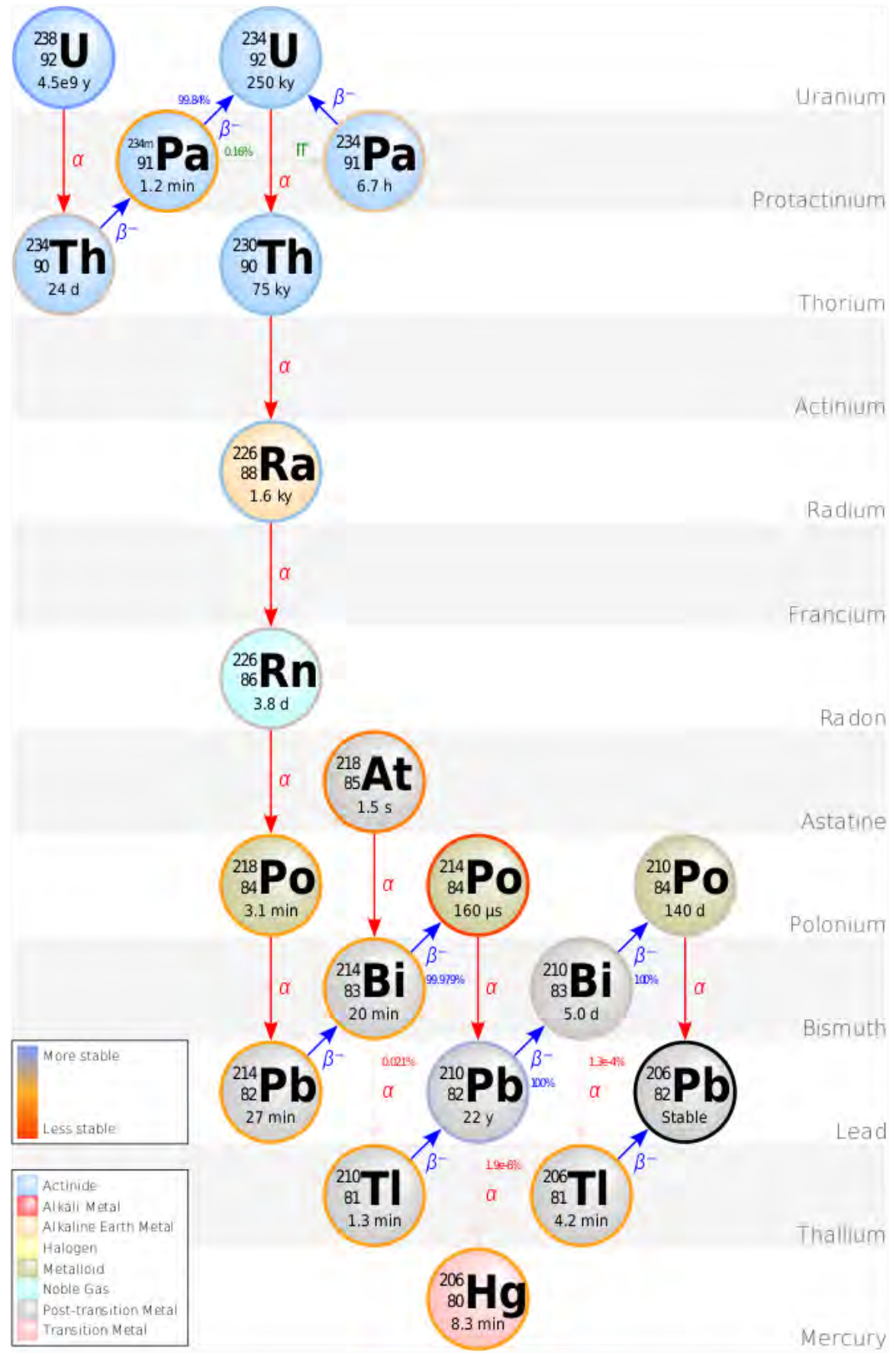

Figure 24. Decay scheme of uranium series (figure used with permission under Creative Commons license) 


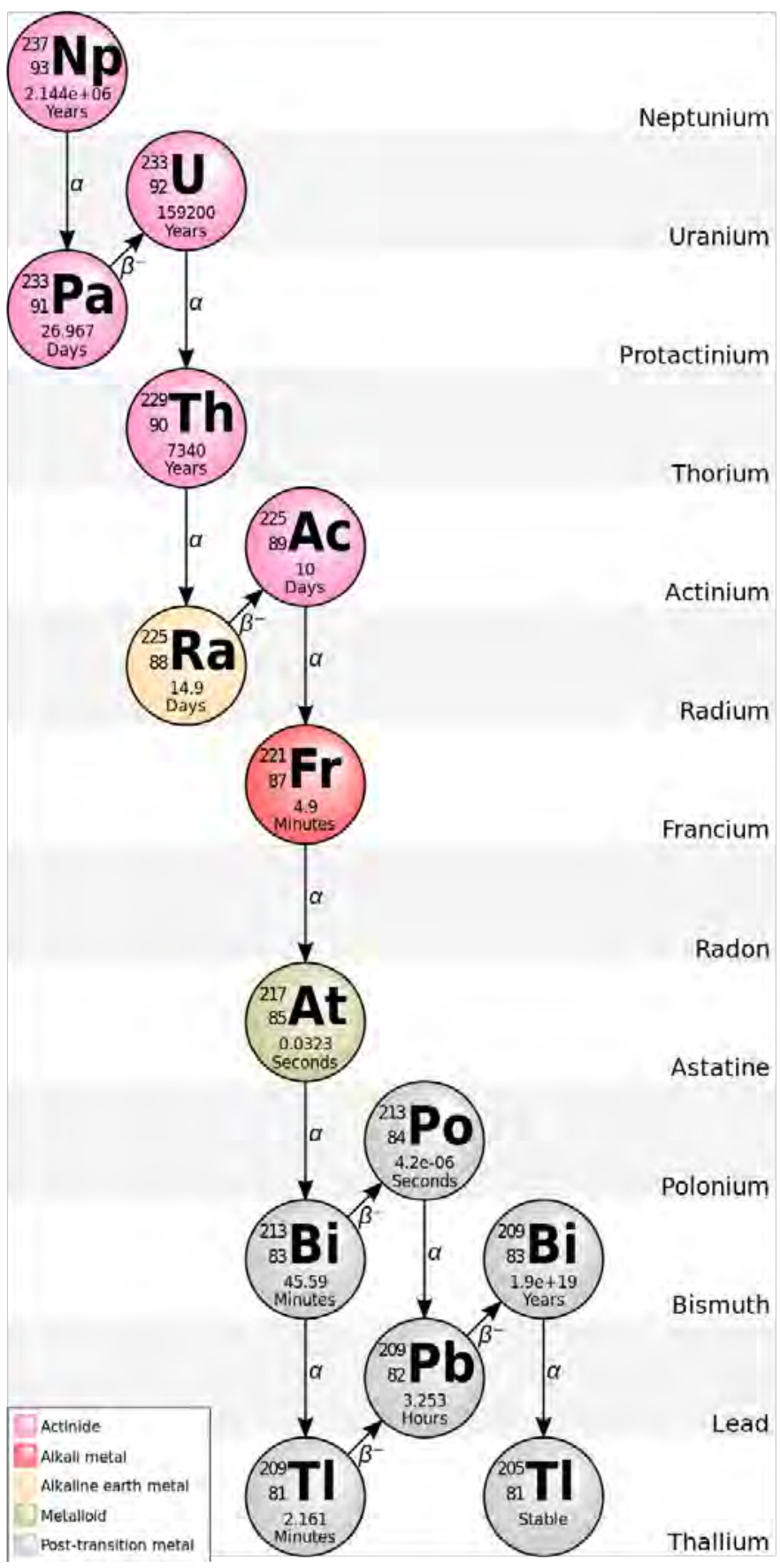

Figure 25. Decay scheme of neptunium series (figure used with permission under Creative Commons license) 


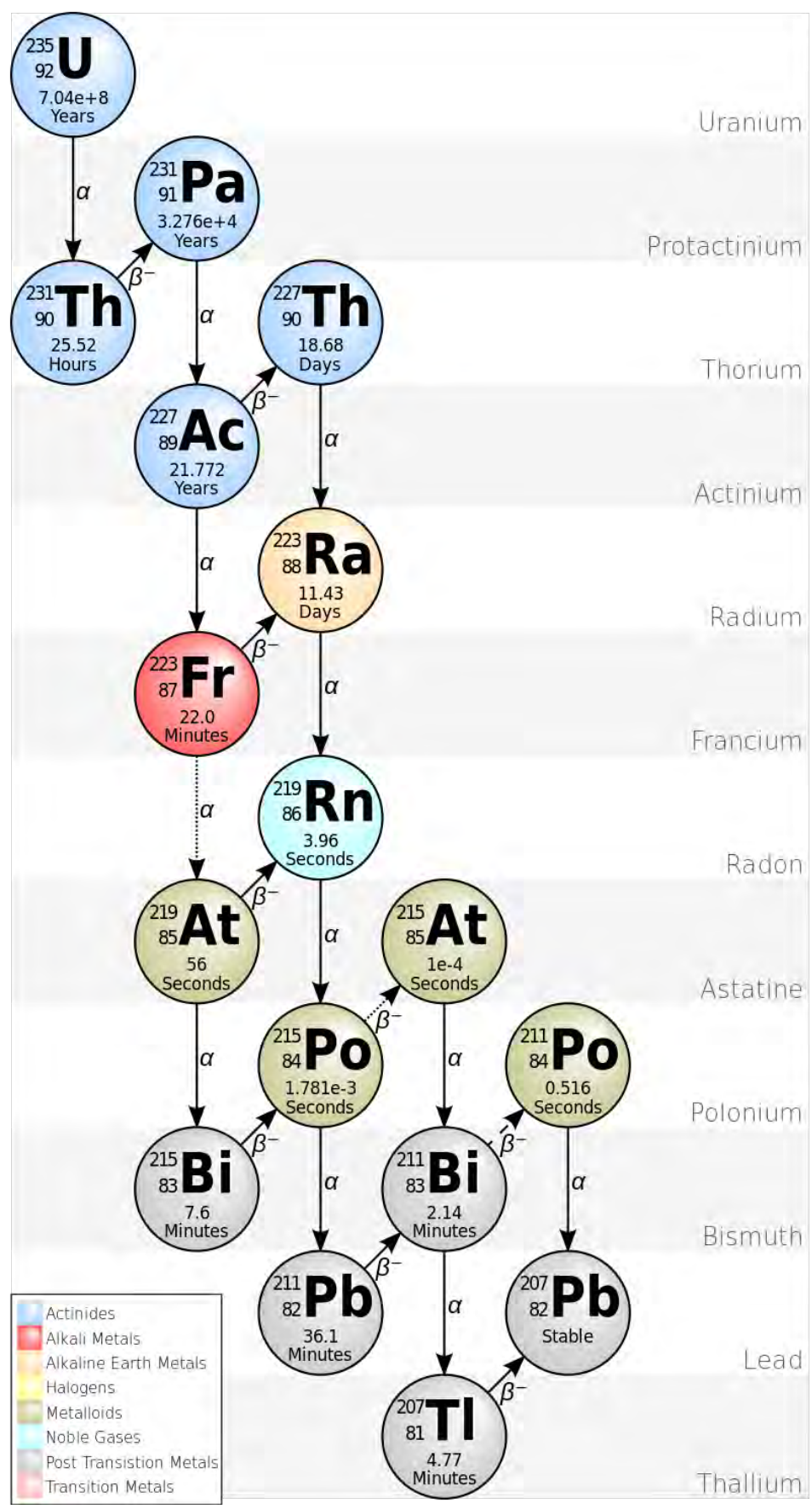

Figure 26. Decay scheme of actinium series (figure used with permission under Creative Commons license) 


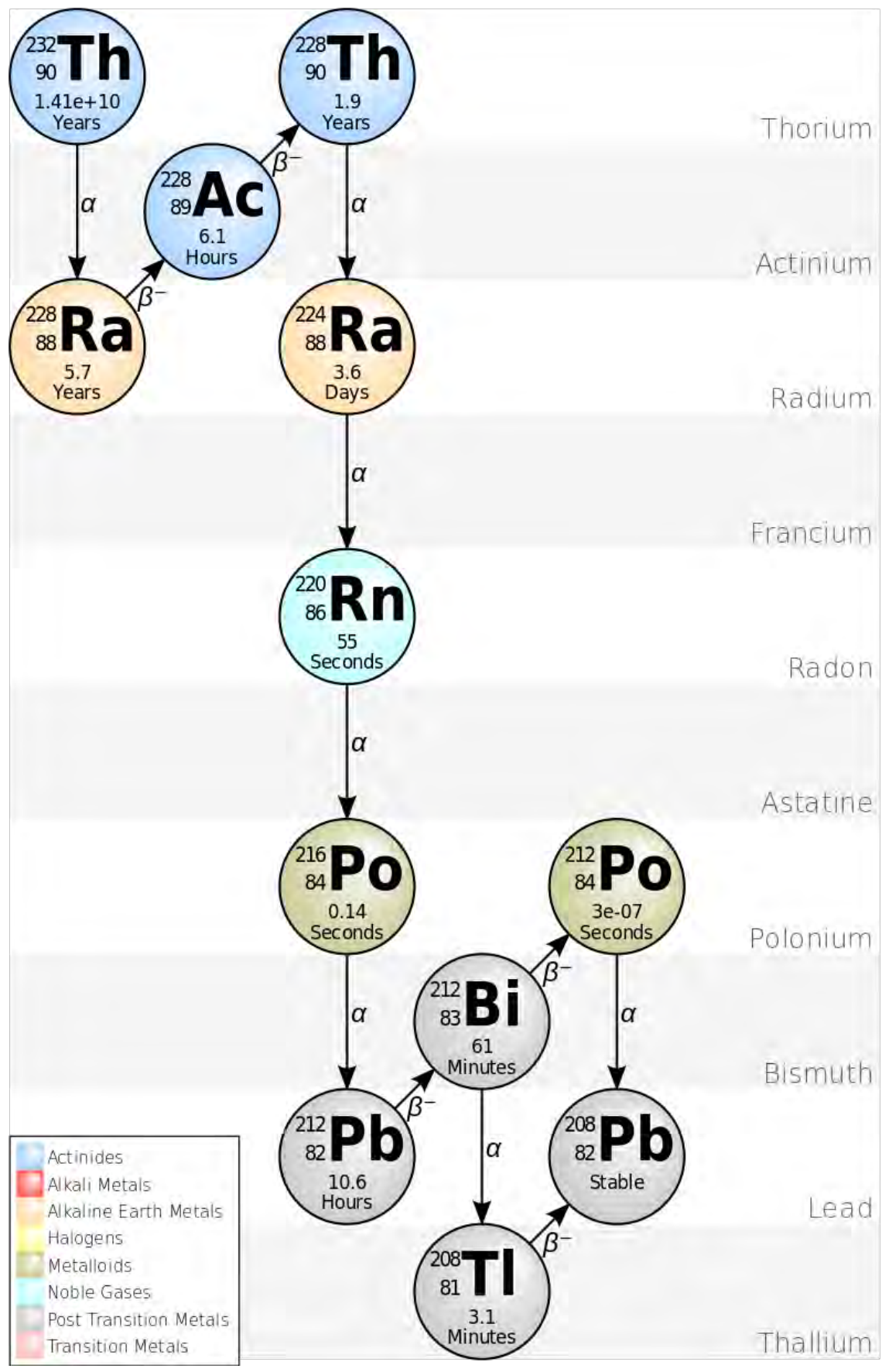

Figure 27. Decay scheme of thorium series (figure used with permission under Creative Commons license) 


\subsection{Radioactive elements produced artificially (by man)}

In the national economy, ionizing radiation is widely used:

- In industry;

- In medicine;

- In security-related departments.

Most isotopes are produced in nuclear reactors and accelerators. They are mostly gamma and beta-radioactive.

\subsubsection{Isotopes used in the medicine}

When used in Medicine, radioisotopes fall into one of two groups:

- Diagnostic Radionuclides

- Therapeutic Radionuclides

A representative list of medical radioisotopes is shown in the table.

$\begin{array}{lll}\text { Sodium-24 }\left({ }^{24} \mathrm{Na}\right) & 15 \text { Hours } & \text { Study of general biological processes } \\ \text { Iron - 59 }\left({ }^{59} \mathrm{Fe}\right) & \mathbf{4 6 . 3} \text { Days } & \text { Diagnosis of Blood Disease } \\ \text { Technetium }-99 \mathrm{~m}\left({ }^{\mathrm{Mm}} \mathrm{Tc}\right) & 6 \text { Hours } & \text { Diagnosis of various diseases } \\ \text { Cobalt }-60\left({ }^{60} \mathrm{Co}\right) & 5.3 \text { Years } & \text { Treatment of Cancer } \\ \text { Strontium }-90\left({ }^{90} \mathrm{Sr}\right) & 27.7 \text { Years } & \text { Treatment of Tumors } \\ \text { Iodine-131 }\left({ }^{131} \mathrm{l}\right) & 2.6 \text { Minutes } & \end{array}$

\subsubsection{Radioisotopes used in the industry}

Table 1. List of radioisotopes use in industry

\begin{tabular}{|l|l|}
\hline \multicolumn{1}{|c|}{ Radioisotope } & \multicolumn{1}{c|}{ Industrial Applications } \\
\hline Americium-241 & $\begin{array}{l}\text { For uniform thickness when rolling steel and paper, determine } \\
\text { location of oil wells }\end{array}$ \\
\hline Sodium-24 & Oil well studies and to locate leaks in pipe lines \\
\hline Iridium-192 & Test integrity of boilers and aircraft parts \\
\hline Uranium-235 & $\begin{array}{l}\text { Nuclear power plant and naval propulsion systems fuel, produc- } \\
\text { tion of fluorescent glassware and colored wall tiles }\end{array}$ \\
\hline Califomium-252 & $\begin{array}{l}\text { Determine moisture content of soil - important for road con- } \\
\text { struction and building industries }\end{array}$ \\
\hline
\end{tabular}




\subsection{Nuclear fuel}

The following table lists of the nuclear reactor core including the fuel type.

\begin{tabular}{|l|l|l|l|l|}
\hline \multicolumn{1}{|c|}{ Reactor Type } & \multicolumn{1}{|c|}{ Coolant } & Moderator & \multicolumn{1}{|c|}{ Fuel } & \multicolumn{1}{c|}{ Comment } \\
\hline $\begin{array}{l}\text { Pressurised water re- } \\
\text { actors (PWR, WER) }\end{array}$ & $\begin{array}{l}\text { Light } \\
\text { water }\end{array}$ & $\begin{array}{l}\text { Light } \\
\text { water }\end{array}$ & $\begin{array}{l}\text { Enriched } \\
\text { uranium }\end{array}$ & $\begin{array}{l}\text { Steam generated } \\
\text { in secondary loop }\end{array}$ \\
\hline $\begin{array}{l}\text { Boiling water } \\
\text { reactors } \\
\text { (BWR) }\end{array}$ & $\begin{array}{l}\text { Light } \\
\text { water }\end{array}$ & $\begin{array}{l}\text { Light } \\
\text { water }\end{array}$ & $\begin{array}{l}\text { Enriched } \\
\text { uranium }\end{array}$ & $\begin{array}{l}\text { Steam from boil- } \\
\text { ing water fed to } \\
\text { turbine }\end{array}$ \\
\hline $\begin{array}{l}\text { Pressurised heavy wa- } \\
\text { ter reactor (PHWR) }\end{array}$ & $\begin{array}{l}\text { Heavy } \\
\text { water }\end{array}$ & $\begin{array}{l}\text { Heavy } \\
\text { water }\end{array}$ & $\begin{array}{l}\text { Natural } \\
\text { uranium }\end{array}$ & - \\
\hline $\begin{array}{l}\text { Gas-cooled reactors } \\
\text { (Magnox, AGR, } \\
\text { UNGG) }\end{array}$ & CO 2 & Graphite & $\begin{array}{l}\text { Natural or } \\
\text { unriched } \\
\text { uranium }\end{array}$ & - \\
\hline $\begin{array}{l}\text { Light water graphite } \\
\text { reactors (RBMK) }\end{array}$ & $\begin{array}{l}\text { Pressurised } \\
\text { boiling } \\
\text { water }\end{array}$ & Graphite & $\begin{array}{l}\text { Enriched } \\
\text { uranium }\end{array}$ & $\begin{array}{l}\text { Soviet } \\
\text { design }\end{array}$ \\
\hline
\end{tabular}




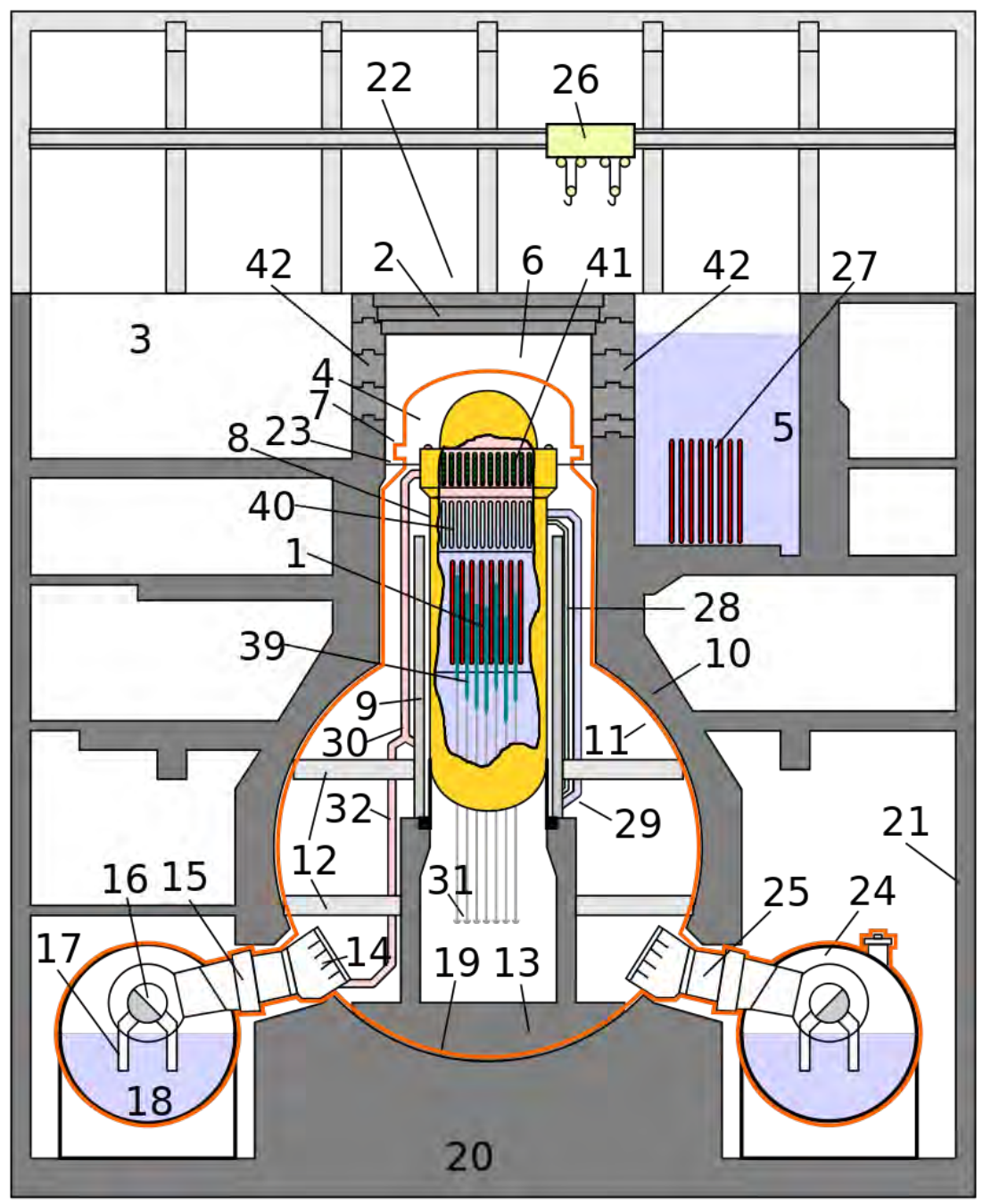

Figure 28. Scheme of BWR nuclear reactor Mark 1 (figure used with permission under Creative Commons license)

Description to figure:

- orange: primary containment vessel:

1 - Core with fuel rods;

7 - Drywell flange;

2 - Concrete shield plug;

8 - Reactor pressure vessel;

3 - Equipment pool;

9 - Biological shield;

4 - Drywell head;

10 - Secondary concrete shield wall;

5 - Fuel storage pool; spent fuel area;

6 - Refueling cavity;

11 - Free standing steel drywell;

12 - Radial beam; 
13 - Concrete embedment;

14 - Jet deflector;

15 - Expansion bellows;

16 - Vent header;

17 - Downcomer pipe;

18 - Water (wetwell);

19 - Embedded shell region;

20 - Basement;

21 - Reactor building;

22 - Refueling platform;

23 - Refueling Bulkhead;
25 - Vent (81 inch diameter);

26 - Crane;

27 - Spent Fuel;

28 - Coolant pipe;

29 - Cold water pipe (from generator);

30 - Steam pipe (to generator);

31 - Control rod drives;

32 - Blow down line;

39 - Control rods;

40 - Steam separators (water normally goes to this level);

41 - Steam dryer;

42 - Gates (removed during refuelling).

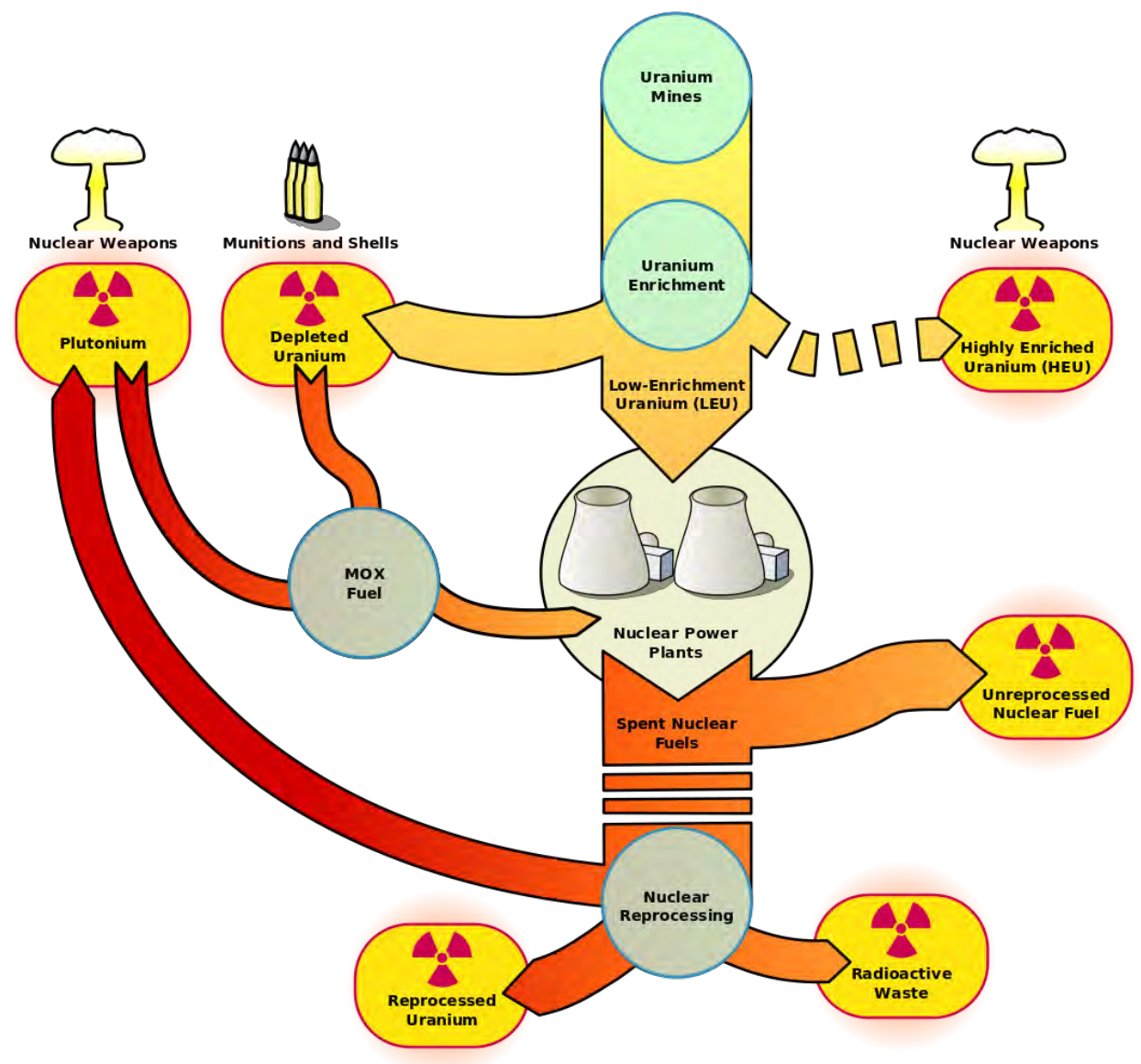

Figure 29. Nuclear fuel process (figure used with permission under Creative Commons license) 


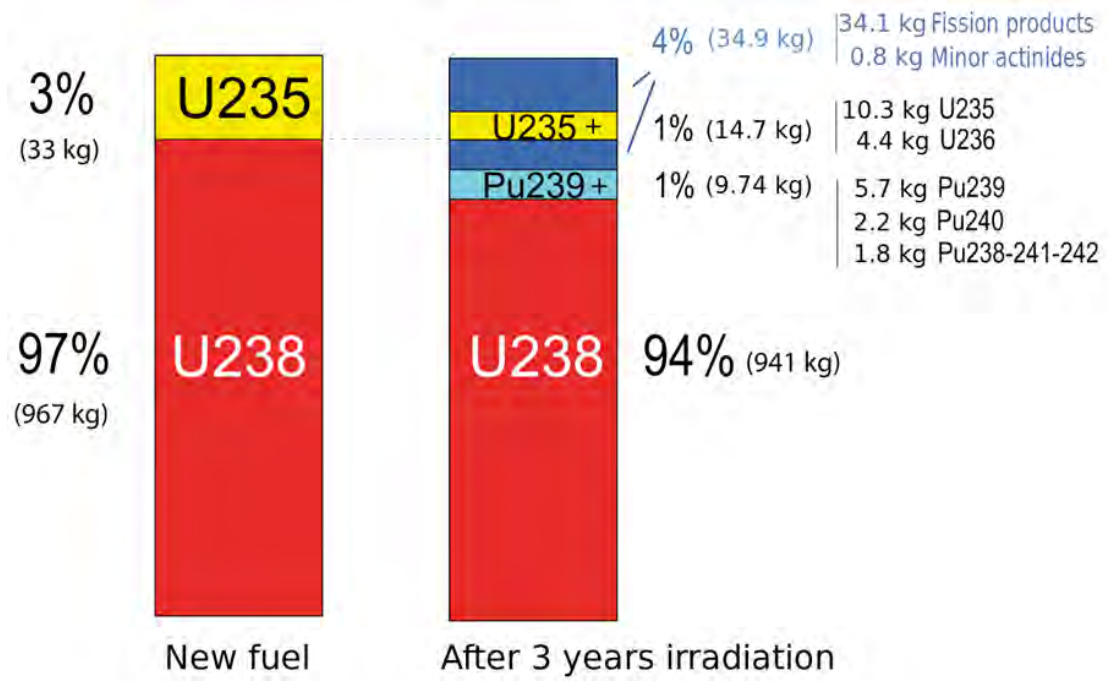

Figure 30. Nuclear fuel composition (figure used with permission under Creative Commons license)

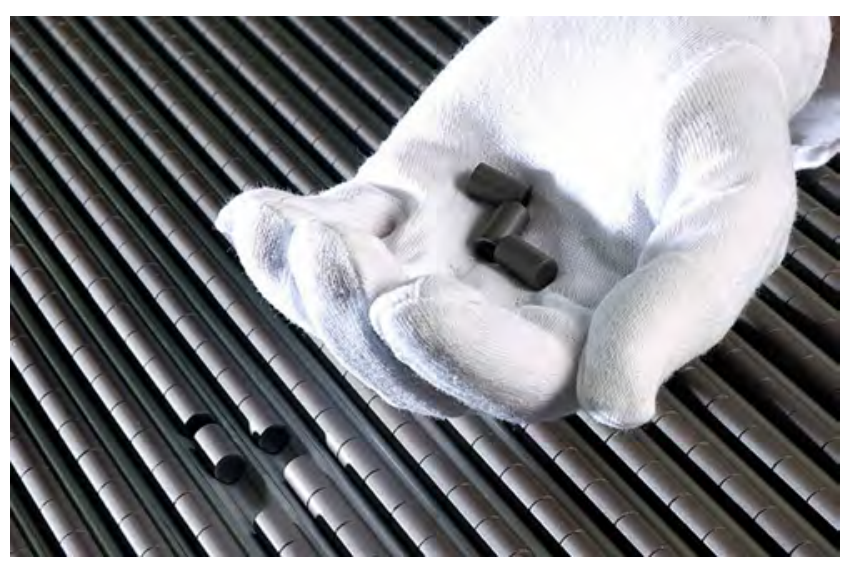

Figure 31. Nuclear fuel pellets (figure used with permission under Creative Commons license)

\subsection{Radioactive waste}

Polish "Atomic Law Act" has a number of articles devoted to radioactive waste. Generally, the waste can be divided into:

- Solid and liquid;

- Low- medium and high-intensity;

- Short and long-lived. 
The law also defines the rights and duties of the Department of Radioactive Waste Management (DRWM) and functioning KSOP (National Radioactive Waste Repository).

The DRWM operates on the premises and in the structure of the NCBJ (National Center for Nuclear Research). On the website of the department you can find out about the conditions of waste collection also the current price list is included.

During the operation of the energy reactor, the so-called fuel cycle. It consists in the fact that during operation some of the rods is "burned" in the exchange requires fresh.

The fired rods are material to be processed in spent fuel processing plants. Part of the fuel is designed for reuse. The rest is considered as radioactive waste and requires appropriate treatment.

Because Poland belongs to IAEA (International Atomic Energy Agency) we are obliged to fulfill all requirements about treatment of radioactive waste which Agency recommend its members. Below you will find how radioactive waste are classified by IAEA.

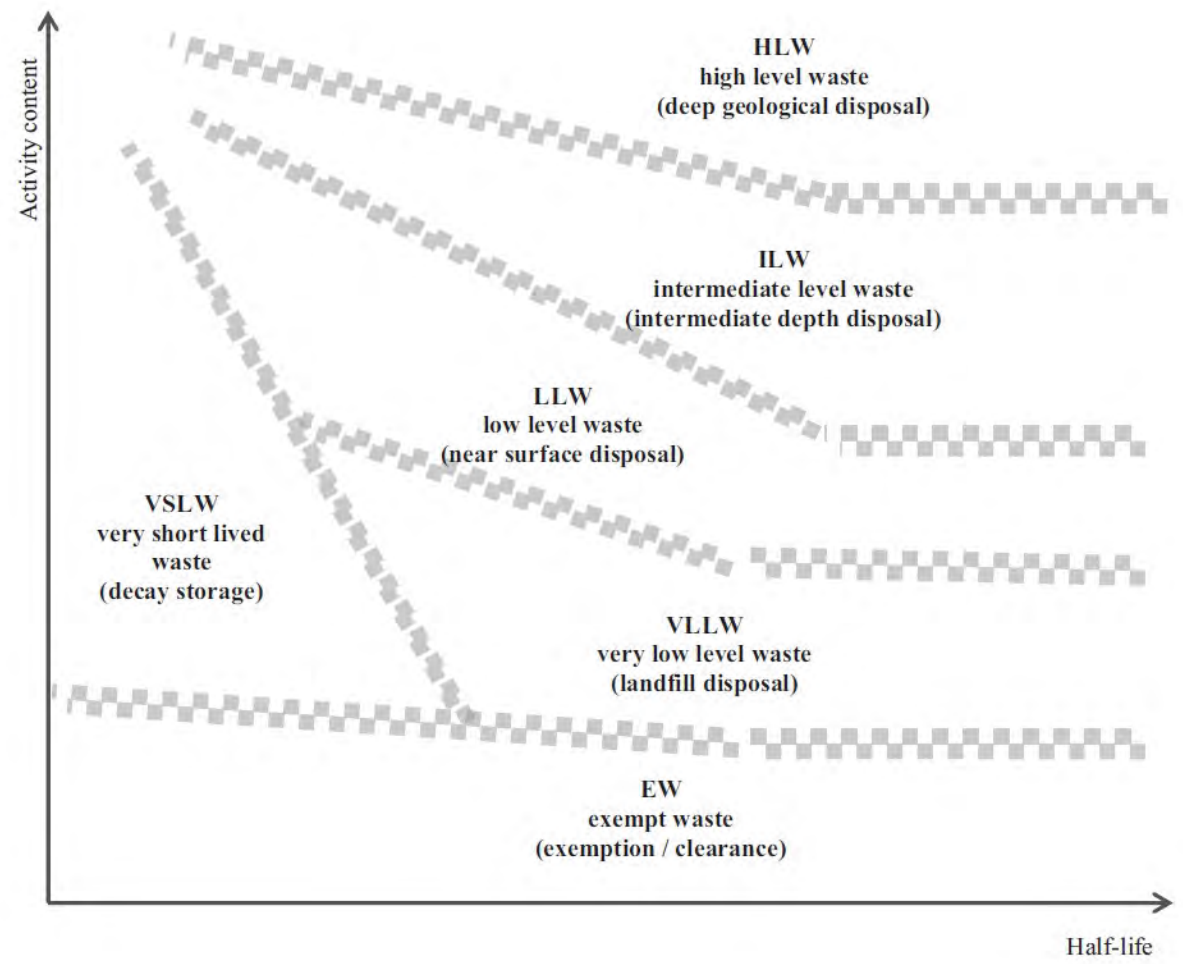

Figure 32. Nuclear waste classification (figure used with permission under Creative Commons license) 

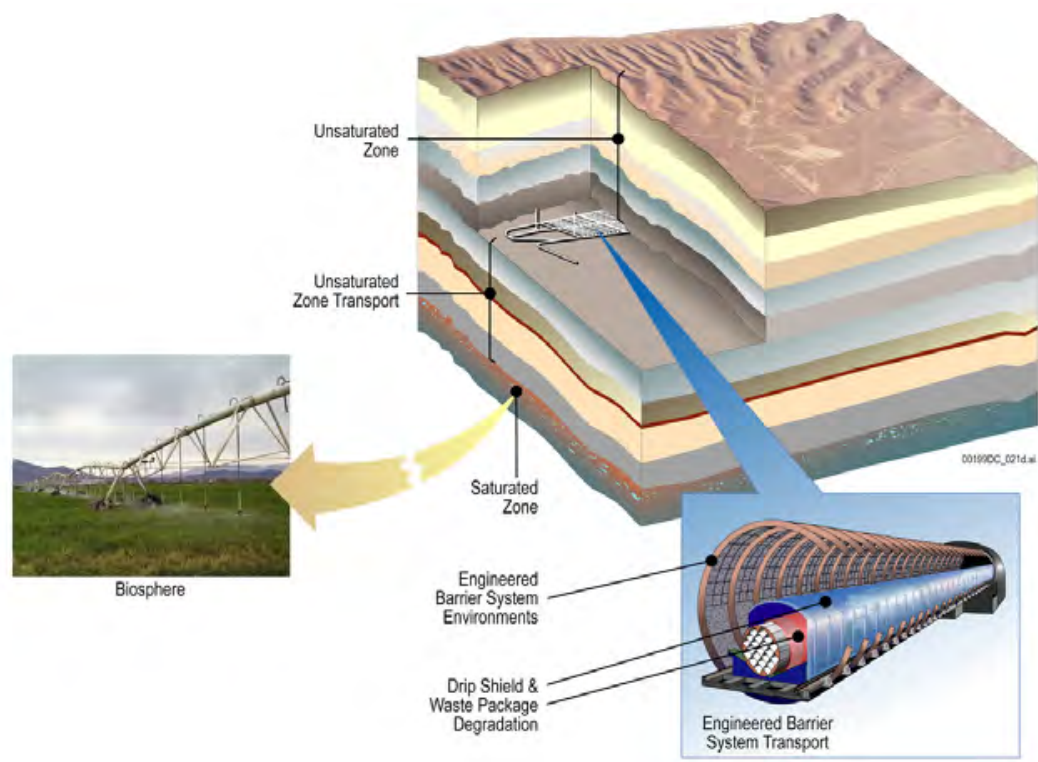

Figure 33. Yucca Mountain nuclear waste repository cross-section (figure used with permission under Creative Commons license)

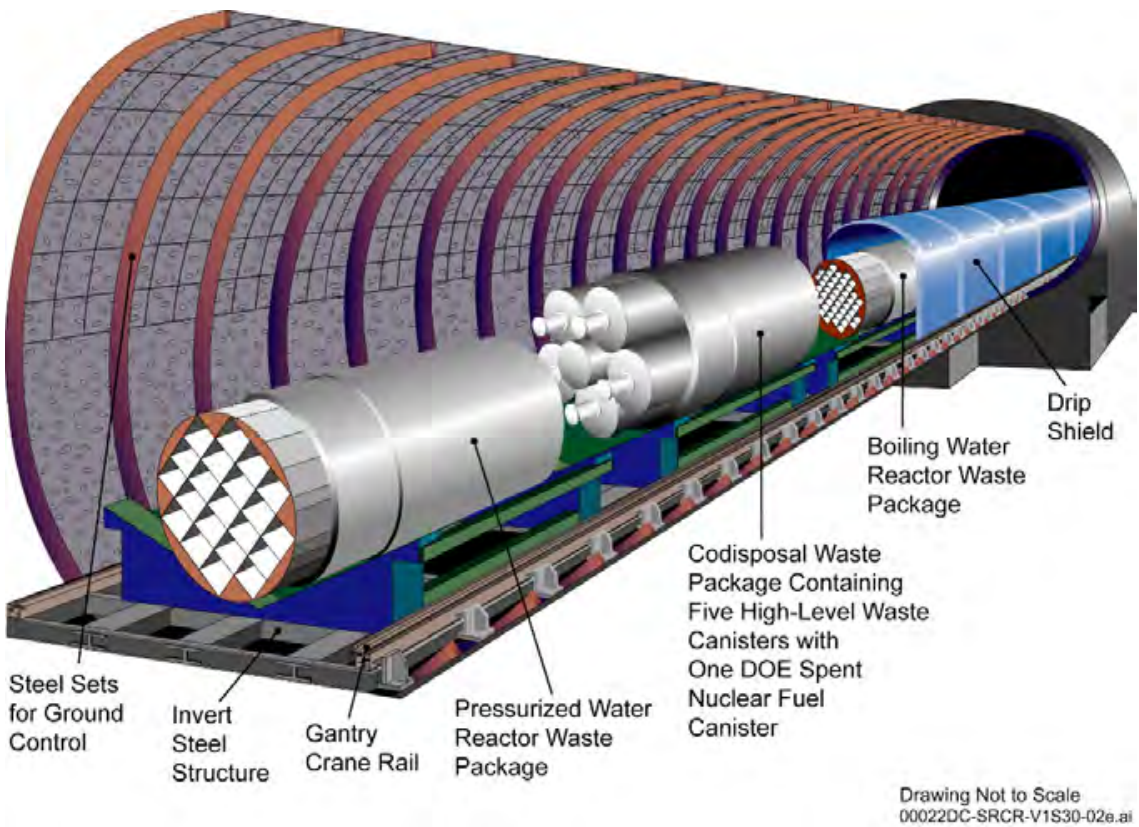

Figure 34. Yucca Mountain waste packages (figure used with permission under Creative Commons license) 


\section{References}

Gale P., Lax E., Radiation: What It Is, What You Need to Know, Knopf, New York 2013. Grupen C., Rodgers M., Radioactivity and Radiation, Springer, Germany 2016.

Janiak M., Cheda A., Nowosielska E., Pokojowe $i$ terrorystyczne zagrożenia radiacyjne, Wojskowa Akademia Techniczna, Warszawa 2012.

Stathaki S., The physics of radiation therapy, Medical Physics, 2010, no. 37(3).

Summary of Yucca Mountain Oversight and Impact Assessment Findings. State of Nevada 1997.

United Nations Scientific Committee on the Effects of Atomic Radiation. Sources, effects and risks of ionizing radiation, 1988.

United Nations. Scientific Committee on the Effects of Atomic Radiation. Sources and effects of ionizing radiation: sources. Vol. 1. United Nations Publications, 2000. 